\title{
Socioeconomic Development in the Bronze Age: Archaeological Understanding of the Transition from the Early to Middle Bronze Age, South Korea
}

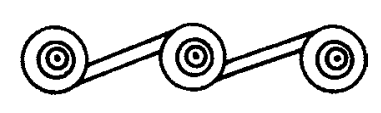

BUMCHEOL KIM

\section{INTRODUCTION}

The PRocesses CONTRIBUting TO THE DEVELOPMENT OF COMPLEX SOCIAL ORGANIZATIONS IN PAST SOCIETIES have long been hotly debated. A number of scholars have focused on more general and more systemic evolutionary processes involving ecological, demographic, economic, social, and ideological factors in the emergence of hierarchical social relations. More recently, archaeologists (and researchers in other social disciplines) have embraced more dynamic models focusing on human actors and their complex choices. Those following the latter approach use the intuitive metaphor of games, including players, rules, and circumstances, to emphasize the dynamic decision making of individuals and groups in specific social and environmental landscapes (Drennan 2000).

Since the mid-2000s, Korean archaeologists have rigorously discussed when and how complex social organizations developed during the prehistory of the central and southern Korean Peninsula (Kim 2005, 2014b; J. Kim 2003a, 2008a). Thus far, scholars broadly agree that social complexity in the Korean context seems to have begun during the Bronze Age, in particular during the transition from the Early to Middle Bronze Age (hereafter EBA and MBA, respectively). The transition is characterized by the formation of Songguk-ri type material culture and its spread into most parts of South Korea. This consensus comes from the recognition of changes along several socioeconomic dimensions including aspects of social organization, subsistence and craft production, and mortuary practices and ritual activities.

Despite the overall consensus, the results of changes in each of the dimensions, how the processes of change in each dimension related to other transformations, and how the changes as a whole contributed to increased social complexity have all been debated. These debates are closely related to questions posed by archaeologists studying complex social development in other regions of the world; hence, research on the Korean Bronze Age is likely to provide important information for cross-cultural studies. Comparative approaches to these issues have been taken as a useful and

Bumcheol Kim is an associate professor in the Department of Archaeology and Art History, Chungbuk National University, Republic of Korea. 
important venue for both modeling and theorization (Drennan 1992; Earle 1997; Feinman and Neitzel 1984; Price and Feinman 1995; Smith 2012). In attempting to understand the socioeconomic changes that occurred during this significant transition period in Korean societies, archaeological discourses concerning the development of social complexity and case studies from other regions of the world will be frequently referred to here. By adopting a comparative approach, we can analyze the various ways in which the Korean case is compatible or incompatible with generalized models of social development, as well as its consistency with specific comparative cases.

One of the most apparent examples of incompatibility is found when scholars apply generalized societal typological schemes to Korean prehistory (Choi 1984). Pointing out fundamental problems in applying any grand theory of social evolution as a package deal of necessary components (i.e., a checklist of specific changes that must occur in tandem), this author, in earlier publications, has emphasized that developing models based on the Korean evidence would better illuminate changes in specific social dimensions and their relationships (Kim 2011d, 2012b). There is considerable potential for Korean archaeology to produce its own models to explain the rise of social complexity in the region. In turn, growing archaeological data sets of high resolution and density may contribute to broader comparative studies (Kim 2011d).

In this light, it seems worthwhile to explore how the case of the Korean EBAMBA transition might contribute to cross-cultural studies of emerging social complexity and compare social processes inferred from the Korean archaeological evidence to other cases from different parts of the globe. Archaeologists are raising a comprehensive set of issues relevant to social complexity in Korean prehistory and developing various discourses to support their theories using archaeological data that have been accumulated quite recently. This article therefore reviews work on Bronze Age social development in Korea in order to more widely disseminate recent contributions of Korean scholars to the discipline of archaeology in general and Bronze Age archaeology in particular.

\section{ARCHAEOLOGICAL RECONSTRUCTION OF THE EBA-MBA TRANSITION}

\section{Chronology and Sociocultural Development in the Bronze Age}

Based on stylistic variations of several types of archaeological features (mostly dwellings and burials) and artifacts (mostly ceramics, bronzes, and lithics), the Korean Bronze Age can be broken down into four subperiods: Incipient Bronze Age (IBA), Early Bronze Age (EBA), Middle Bronze Age (MBA), and Late Bronze Age (LBA). Each subperiod can be characterized by prevalent local types of assemblages (Fig. 1).

Incipient Bronze Age (IBA) - The IBA (1500-1300 B.C.E.) can be characterized by the emergence of a Misa-ri type cultural assemblage composed of rectangular or squared houses with hearths surrounded by stone slabs or gravels, deep pottery bowls with doldaegakmokmun (돌대각목문, notched clay bands), and stone tools (Fig. 2). Less than 30 sites are represented in the corpus of IBA finds that have been discovered since the early 1990 s.

In comparison to other subperiods of the Bronze Age and even Late Neolithic (hereafter LN), the number of sites affiliated with the IBA is quite small. The scarcity 


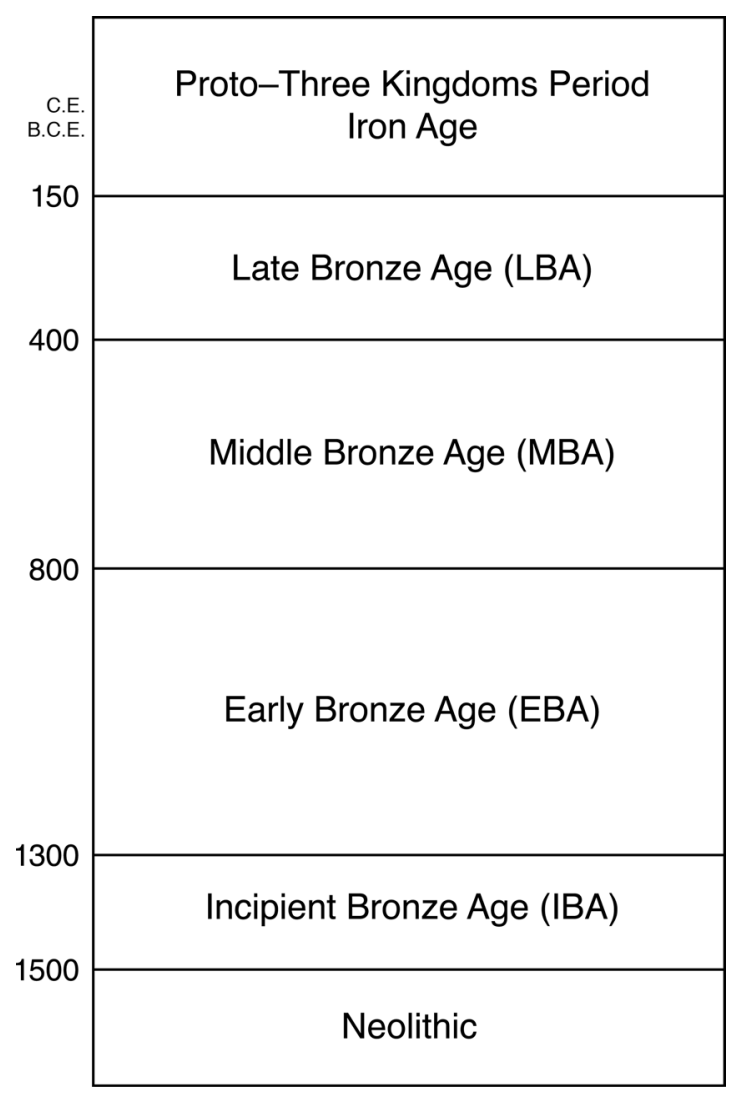

Fig. 1. Chronological scheme for the Korean Bronze Age.

of discovery, incompatibility with artifact styles from the hypothesized donor region (i.e., northwestern Korea), and the instability of absolute dates have led some critics to deny the existence of an IBA phase and consider the Misa-ri type a minor element of local EBA cultures (J. Kim 2008b).

Early Bronze Age (EBA) - The EBA (1300-800 B.C.E.) can be characterized by three local mumun (무문, plain-coarse) pottery styles and (long) rectangular dwellings. The time-space systematics of several local pottery styles have been primarily studied to establish the diffusion routes of material culture and patterns of migration relevant to the formation of Bronze Age culture in the Korean Peninsula. One prevalent explanatory model for EBA culture in the central and southern part of the peninsula can be summarized as the southward advance of the northeastern and northwestern traditions, followed by their combination in the Han River basin (Lee 1974), with some modifications (J. Kim 2001; Park 1999).

The Yeoksamdong, Garakdong, and Heunam-ri styles represent northeastern, northwestern, and combined traditions, respectively. Since attention has been paid to slight differences in associated typical dwelling plan forms and lithic artifacts, each of these pottery styles (defined by characteristic rim-decoration motifs) has been designated an archaeological feature-and-artifact assemblage. The Yeoksamdong-type assemblage is characterized by ceramic vessels, especially urns and deep bowls, 

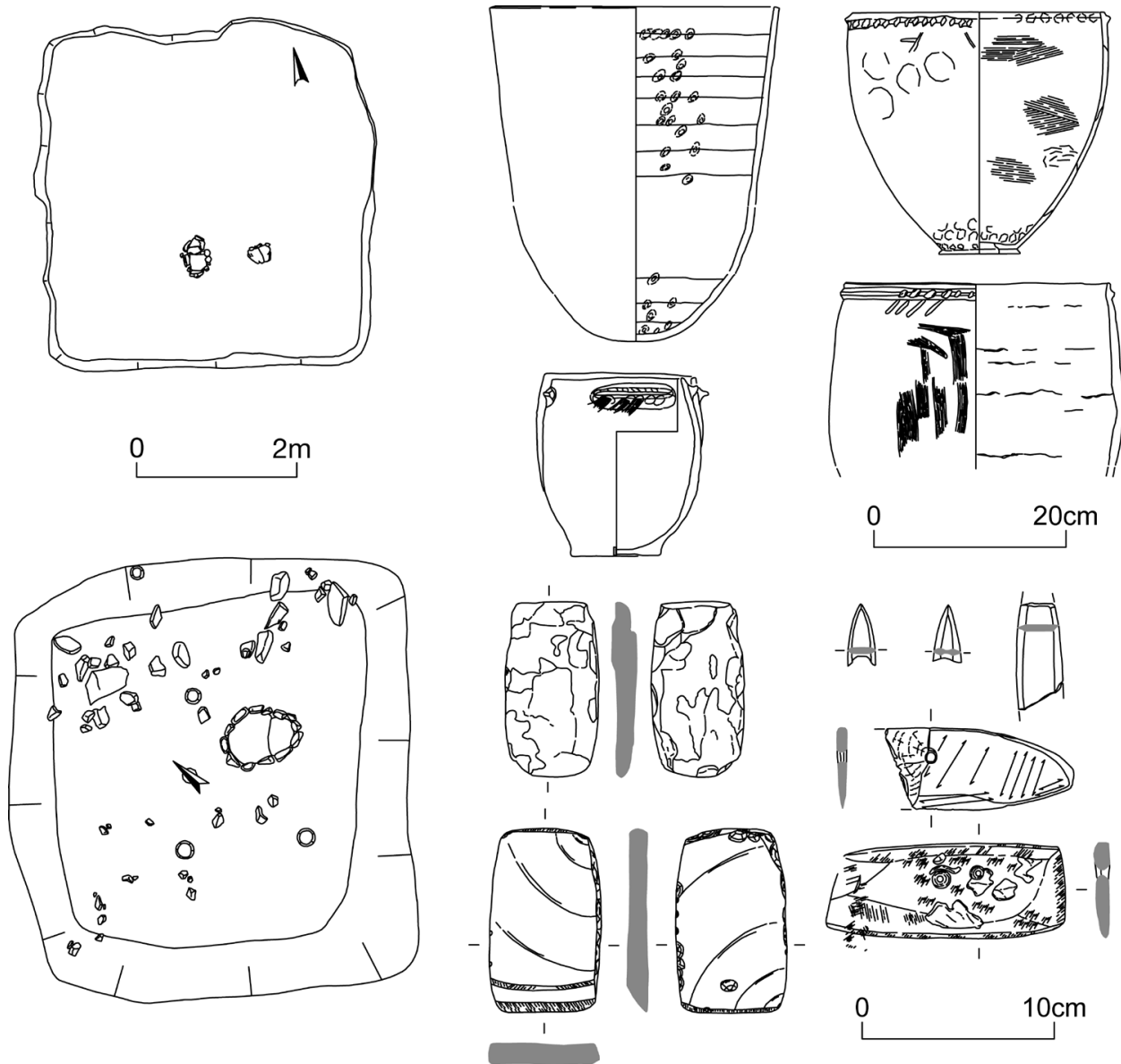

Fig. 2. A Misa-ri type assemblage.

decorated with gongyeol (공렬, line(s) of perforated holes), and associated with rectangular houses with pit hearths (Fig. 3). The Garakdong-type assemblage is represented by ceramic vessels decorated with iejoongguyeon (이중구연, doubled rims) and dansaseon (단사선, short slanted lines) and is associated with rectangular houses with hearths surrounded by stone slabs or gravels (Fig. 3). The Heunam-ri type assemblage looks like the Yeoksamdong type, except it includes ceramic vessels with Garakdongtype decorative motifs (Fig. 3). Scholars favoring this scheme put the temporal order of occurrence of these three types in central and southern Korea as: Yeoksamdong $\rightarrow$ Garakdong $\rightarrow$ Heunam-ri. Proponents for the establishment of an IBA, however, present a different picture of the relationship among the three local styles. In the modified scheme, Garakdong-type assemblages, sometimes found together with Misa-ri type assemblages, are placed earliest; Heunam-ri type assemblages sharing motifs with the Garakdong type are considered the next phase; and the Yeoksamdong-type assemblages are placed last in the sequence.

For some reason, Korean archaeologists have repeatedly emphasized the role of cultural diffusion accompanied by substantial immigration to explain the formation of 

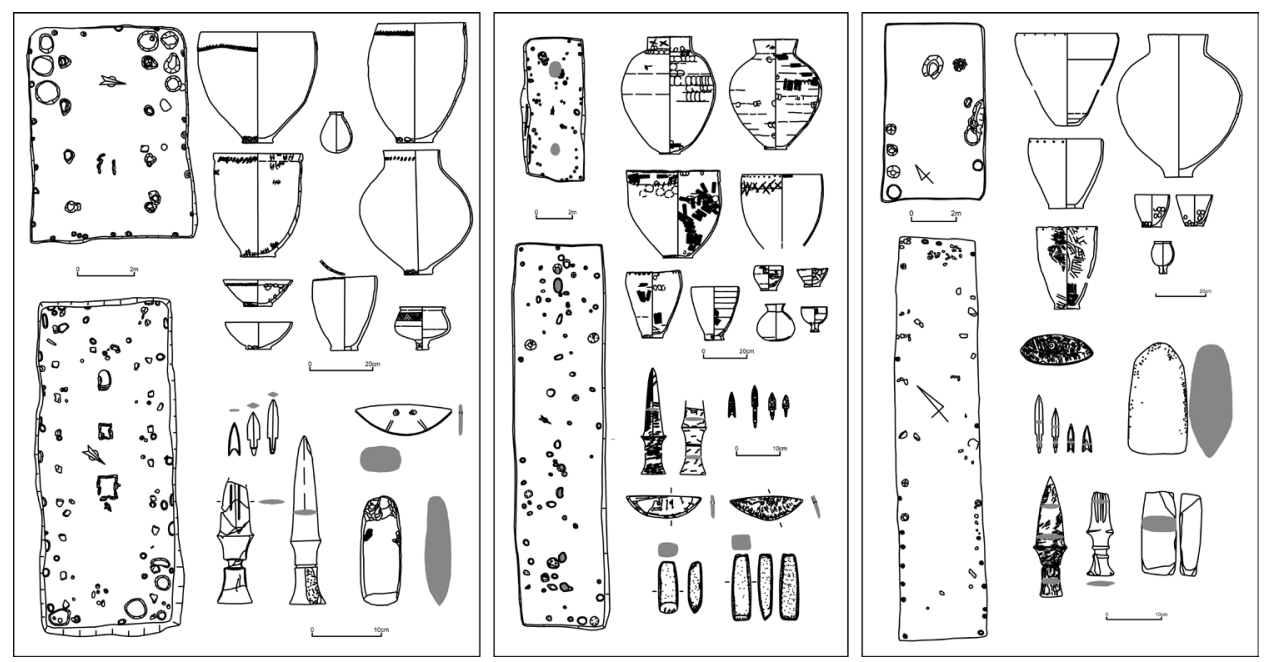

Fig. 3. Three local types of EBA assemblages: Garakdong type (left); Heunam-ri type (center); and Yeoksamdong type (right).

Bronze Age culture in the central and southern part of the peninsula. Despite efforts to find some link between the two archaeological cultures (i.e., LN and IBA/EBA) of the region (J.-H. Ahn 2000; J. Kim 2001; Park 1993a), dissimilarities between them can hardly be denied (J. Kim 2002, 2003a). Those favoring an extreme diffusionist explanation for sociocultural change explained away discontinuities and dissimilarities with the idea of "ethnic replacement" (Kim 1979; Kim 1986). However, interpreting culture change as a shift in ethnicity has rarely been supported by archaeological research. In addition, attempts to substantiate the ethnic replacement model by affiliating Neolithic culture to the Palaeo-asiatic group (a more or less fictional ethnic construction created by modern scholars) or Bronze Age culture to the Tungus have not been successful. Critics of the extreme diffusion perspective have pointed out its logical and empirical problems (Yi 1991). Although such critics have successfully introduced logical limitations to the ethnic replacement theory, they have failed to establish an alternative framework for explaining the dissimilarities and discontinuities between LN and EBA cultures or to identify the processes or causes of a transition from one to another culture (J. Kim 2002).

On the other hand, based on archaeofaunal analysis of shell middens prevalent in the coastal and insular landscapes of the Neolithic, some researchers have recently characterized the LN-EBA transition, accompanied by rice cultivation, as an indigenous sociocultural evolution that solved the population-food imbalance generated by extreme population growth in the late LN (J.-J. Lee 2001; Norton 2000). While their theory explains the adoption of rice agriculture, it is insufficient for understanding all the cultural changes we see in this period (J. Kim 2002). Furthermore, while presenting data on the diminishing returns of marine shell fishing as major evidence for population growth (that would have resulted in overexploitation of marine resources) seems logical (J.-J. Lee 2001), it is an inadequate basis for reconstructing demographic changes in populations residing in inland habitats. In fact, the authors cited above note that marine shellfish as a dietary resource were secondary to cultivated or gathered 
crops and plants and shell middens were produced at short-term collecting camps, not sedentary settlements.

Some critics of "replacement theory" who emphasize the dissimilarities between LN and EBA material cultures and site locations and an increase in rice cultivation have characterized the LN-EBA transition as the importation and spread of a complete package made up of several components and designated the whole as "EBA culture." This package included new material culture such as rectangular houses, northern pottery styles, and relatively developed ground stone tools, a (rice-)farming economy, and even an exclusive land-use strategy (J. Kim 2002, 2003a). This theory suggests that the transition involved an abrupt and discontinuous change from food procurement to crop production. According to Jangsuk Kim (2002, 2003a), evidence indicates that after this shift in subsistence, EBA assemblages throughout the whole of the central and southern peninsula became homogenous. Finally, he concludes that an exclusive land-use strategy, conceptually opposed to the LN patch-sharing strategy, accompanied by immigrant EBA people, was responsible for the rapid spread of EBA culture into the LN context.

Jangsuk Kim's theory is not supported by current empirical data and has some logical flaws, which I now summarize. First of all, contrasting the hunting and gathering (or food-procurement) economy of the LN with the crop-farming economy of the EBA is somewhat subjective and impressionistic; it has never been thoroughly explored, at least not in Jangsuk Kim's research. Much research, especially archeobotanical analyses, has revealed that crop cultivation-most importantly for this study, rice cultivation - not only long preceded the emergence of EBA assemblages but was also almost fully developed prior to the beginning of the EBA (S.-M. Ahn 2000; HNUM 2003; Im 1992, 1997; G.-A. Lee 2003; Nelson 1993). Although it is undeniable that nutritional dependency on crops increased from the LN to the EBA, this does not necessarily mean the economic system changed drastically. In fact, there is no evidence to support the view that EBA residents were much more dependent on rice than LN residents (cf. Norton 2007).

Second, the rapid spread of a specific archaeological culture accompanied by actual long-distance human movement, which is the aspect of the hypothesis advanced to explain the inter-regional homogeneity of EBA material culture, could have been related not to an exclusive land-use strategy (which would have diminished the possibility of finding good land) but at least in part to an extensive agricultural technology such as slash-and-burn cultivation that requires relatively extensive land resources (Im 1997; Ko 2010; NMK 2000; Park 2002). In addition, while rapid long-distance movement and exclusivity of land use seems to be very dependent on the population size, Jangsuk Kim does not pay attention to this variable. Unless there is some other reason for high mobility, under conditions of underpopulation, an exclusive land-use strategy might not have been a very effective mechanism for the rapid spread of material culture. More fundamentally, "rapidity" is subjective and relative. What we see currently are the material remains of a culture covering a period of 500 years. It is thus questionable whether the spread of the farming economy throughout the $90,000 \mathrm{~km}^{2}$ area of southern Korea can be considered rapid. Moreover, Jangsuk Kim's study does not address the 200-year time span or regional settlement patterns of the IBA. IBA villages are not very prevalent on the Korean Peninsula; where they do occur, they often share the same locations as Neolithic villages rather than later EBA villages. There is little substantial data on these villages and we do not have any convincing 
information on how IBA people organized themselves and what their settlement patterns looked like.

Third, Jangsuk Kim's contrast of the land-use strategies of the two periods seems to be based on an analysis of incomparable separate data sets: the LN data come from shell middens on small islands, but the EBA data are derived from inland sites. As most Korean archaeologists would agree, marine shellfish were only a secondary dietary resource; cultivated crops or plants inland were the primary resource. In addition, marine shellfish might have been gathered during short-term trips from inland permanent habitations. No attempt has been made to reconstruct the land-use system or strategy of the inland Neolithic.

Moreover, the EBA land-use strategy has never been thoroughly investigated in a comprehensive archaeological study. Although there are alternative interpretations, some researchers assume that dolmens were "territorial markers" in forwarding the argument that EBA people invested social and physical energy on claiming land tenure rights (Park 1998a). Park's suggestion depends on a rough observation of distributional patterns of dolmens overlapped on an ancient map of transportation routes without any bridging argument or rigorous spatial analysis. Although it can be concluded that dependency on agricultural products increased over time, and that this would have enhanced the importance of claiming land tenure, this issue has never been fully examined in terms of its material implications or actually tested with empirical data. Recent studies suggest that the majority of dolmens were built in the EBA-MBA transition (Kim 2010a; Son 2009). Thus, Park's premise that there is a positive relationship between labor invested in construction and soil productivity cannot be supported by the empirical data (Kim 2010b).

Middle Bronze Age (MBA) - The MBA (800-400 B.C.E.) is characterized by the emergence and spread of Songguk-ri type assemblages into most parts of central and southern Korea. These assemblages are constituted of various kinds of archaeological indicators, such as Songguk-ri type dwellings, Songguk-ri type pottery, some stone tools (triangular ripping knives, grooved stones, and arrowheads) and so on (Fig. 4).

Investigation of the assemblages was initiated by the accidental discovery of a stone slab tomb with a Liaoning-type bronze dagger (Kim and Ahn 1975) (Fig. 5). A couple of excavations were then conducted near the tomb at the Songguk-ri site. Over the next four decades, further discoveries of sites with similar assemblages were made. Researchers analyzed individual artifacts from these sites, mostly with the aim of establishing the chronology (Bae 2001; Cho 1989; Roh 2001; Yi 1992a) and spatial patterning of the sites at various scales (Ahn 1996; Kwon 1997; J.-M. Lee 2003; Song 2001). The majority of Korean archaeologists reached a substantial consensus that the Songguk-ri type assemblage represented an MBA culture extending from centralwestern Korea southward. As a polythetic grouping, the assemblage has been observed to have considerable coherence over a vast area including the Chungcheong, Jeolla, Gyongsang, and even Jeju provinces (Fig. 6). These regions have recently been referred to as the "Songguk-ri Culture Area" by researchers who have recognized that there were several local traditions that did not have far-reaching influence (Lee 2012:13-15) (Fig. 6). Each of these traditions included key aspects of Songguk-ri type assemblages outside the Songguk-ri Culture Area.

Large-scale excavations conducted as part of Cultural Resource Management (CRM) projects have exposed entire settlements, sometimes enclosed by palisades, 


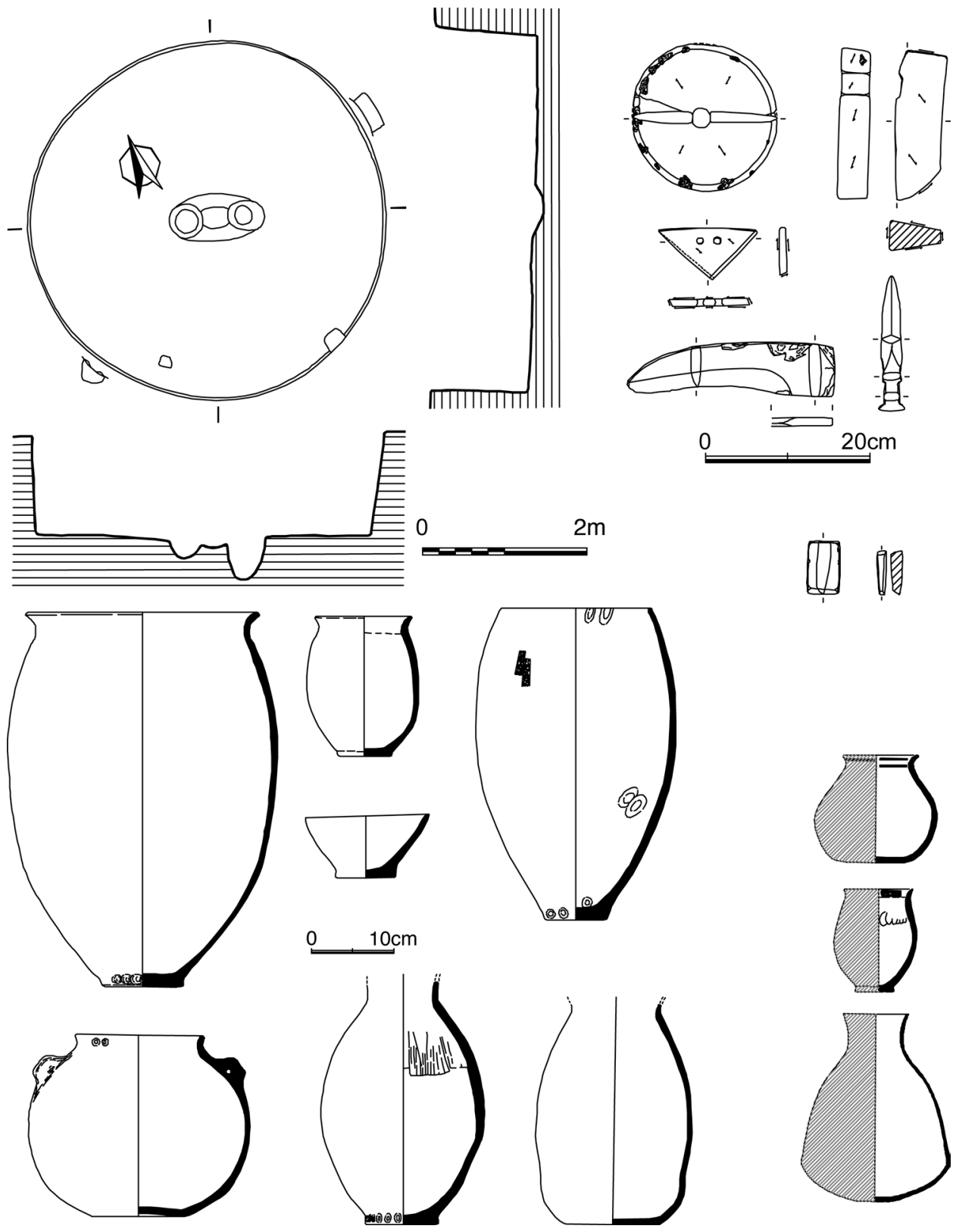

Fig. 4. A Songguk-ri type assemblage.

moats, or ditches, with remnants of adjacent paddy fields. Technical advances in excavation and analytic methodology have identified considerable direct and indirect evidence of a developed system of wet-rice cultivation. This has led Korean archaeologists to pay close attention to the relationship between the emergence and spread of Songguk-ri type assemblages and social changes in the MBA, which they believe resulted in the emergence of large settlements with defensive features (Kim 1998; Lee 


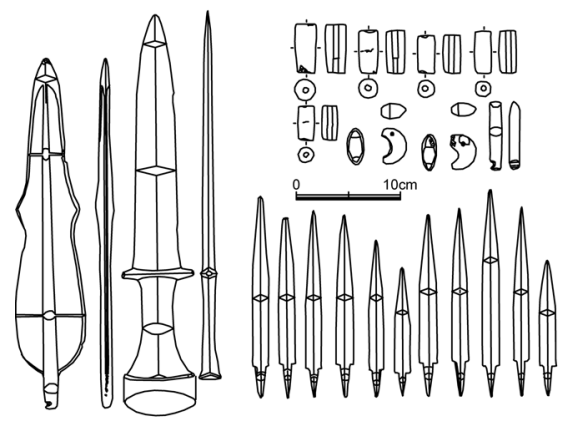

Burial Goods
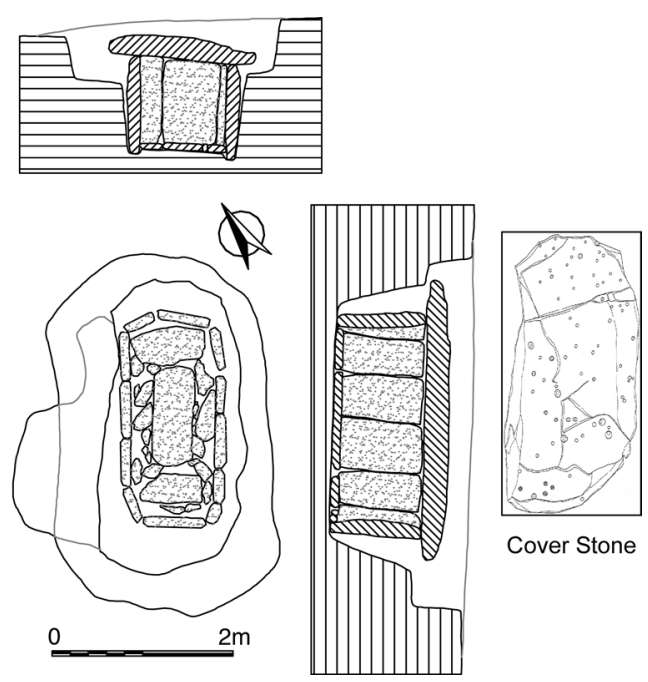

Cover Stone

Fig. 5. Tomb No. 1 from a Songguk-ri site and its burial goods.

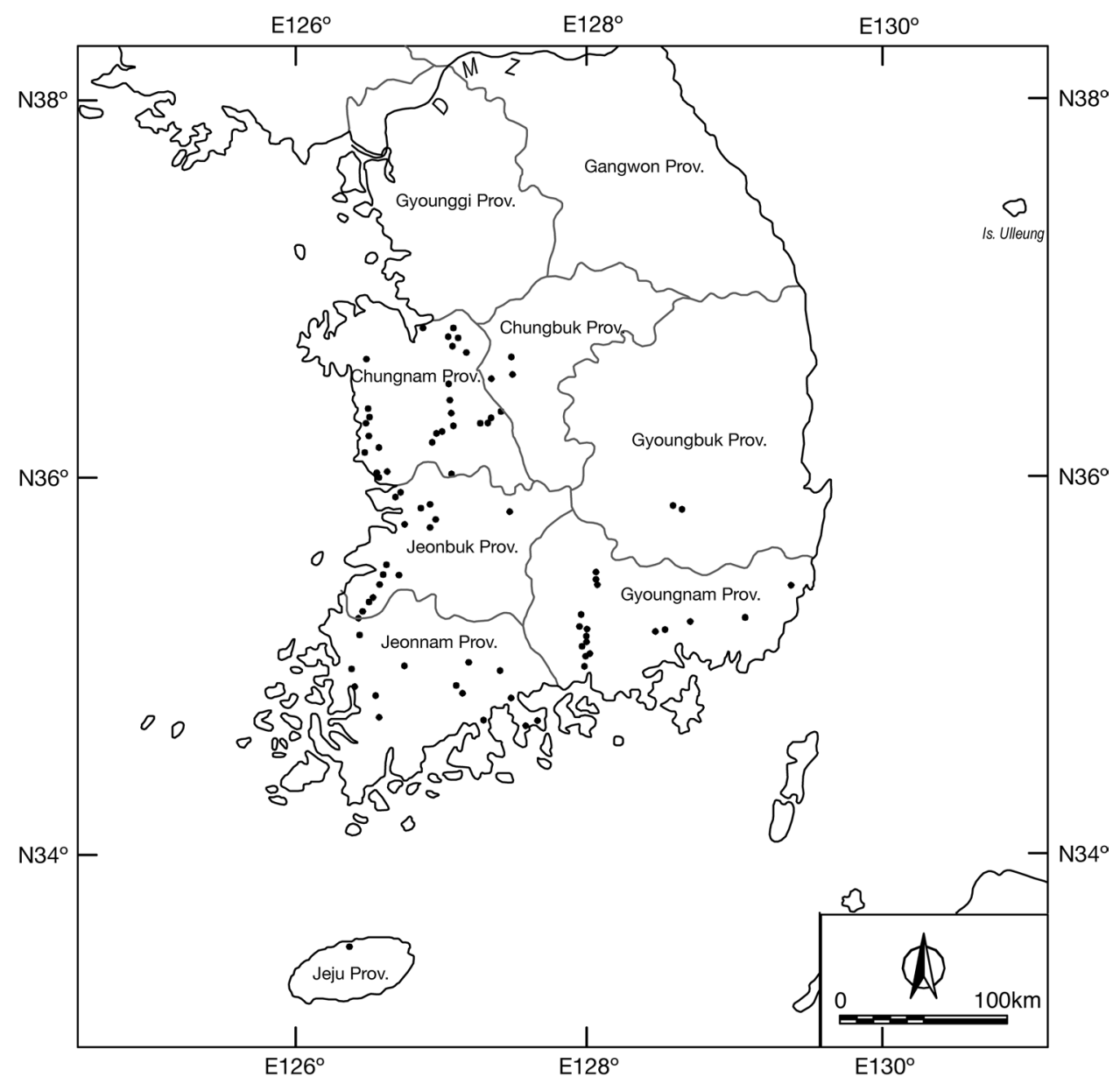

Fig. 6. Distribution of Songguk-ri type sites. Redrawn and modified after H.-S. Kim (2002:19). 


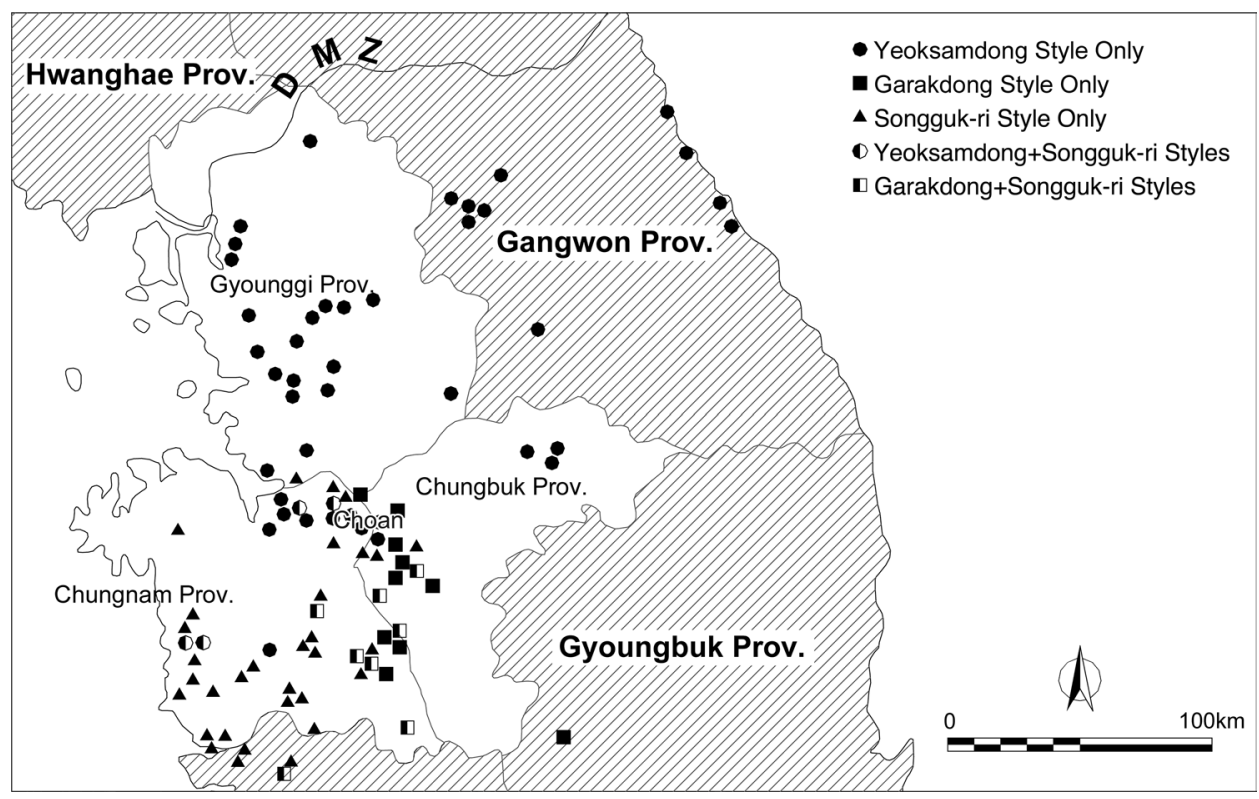

Fig. 7. Distribution of EBA and MBA sites in the central-western Korean Peninsula. Redrawn and slightly modified after J.-M. Lee (2003:17).

2009; NMK 2000). They stress the role of wet-rice cultivation in these sociocultural changes.

Much of the research initiated by attention to these associated changes in archaeological assemblages, settlement organization, and wet-rice farming has concentrated on central-western Korea. Researchers have attempted to explain the remarkable dissimilarities between EBA and MBA material cultures and the apparent separation of EBA/MBA regional settlement distributions (Fig. 7). There is much disagreement among scholars, but their discordant views can be categorized largely into two factions. Emphasizing the dissimilarity and separateness between EBA and MBA material culture and settlement patterns, one group envisions an influx of new cultural elements along with substantial immigration as the source of change. However, so far this group of researchers has not found a donor region or culture from which the Songguk-ri culture originated, nor have they suggested any particular causal factor for the apparent sociocultural changes.

The other group of researchers finds some stylistic links between EBA and MBA assemblages in central-western Korea and suggests that there was an indigenous evolution of the socioeconomic system and invention of new forms of material culture (Ahn 1992; Kim 2003b; Song 2004). This group of scholars has made enthusiastic efforts to connect presumed sociocultural changes ultimately to the replacement of material culture, along with the initiation and prevalence of wet-rice cultivation as an intensive form of rice production. These efforts include establishing an intermediate cultural stage or assemblage between EBA and MBA, the so-called "Pre-Songguk-ri type" (Ahn 1992:21; Kim 2003b). They suggest that local population growth resulted in a food-population imbalance, overexploitation of soil productivity and deterioration of sustained yields, and local population movement into lands suitable for 

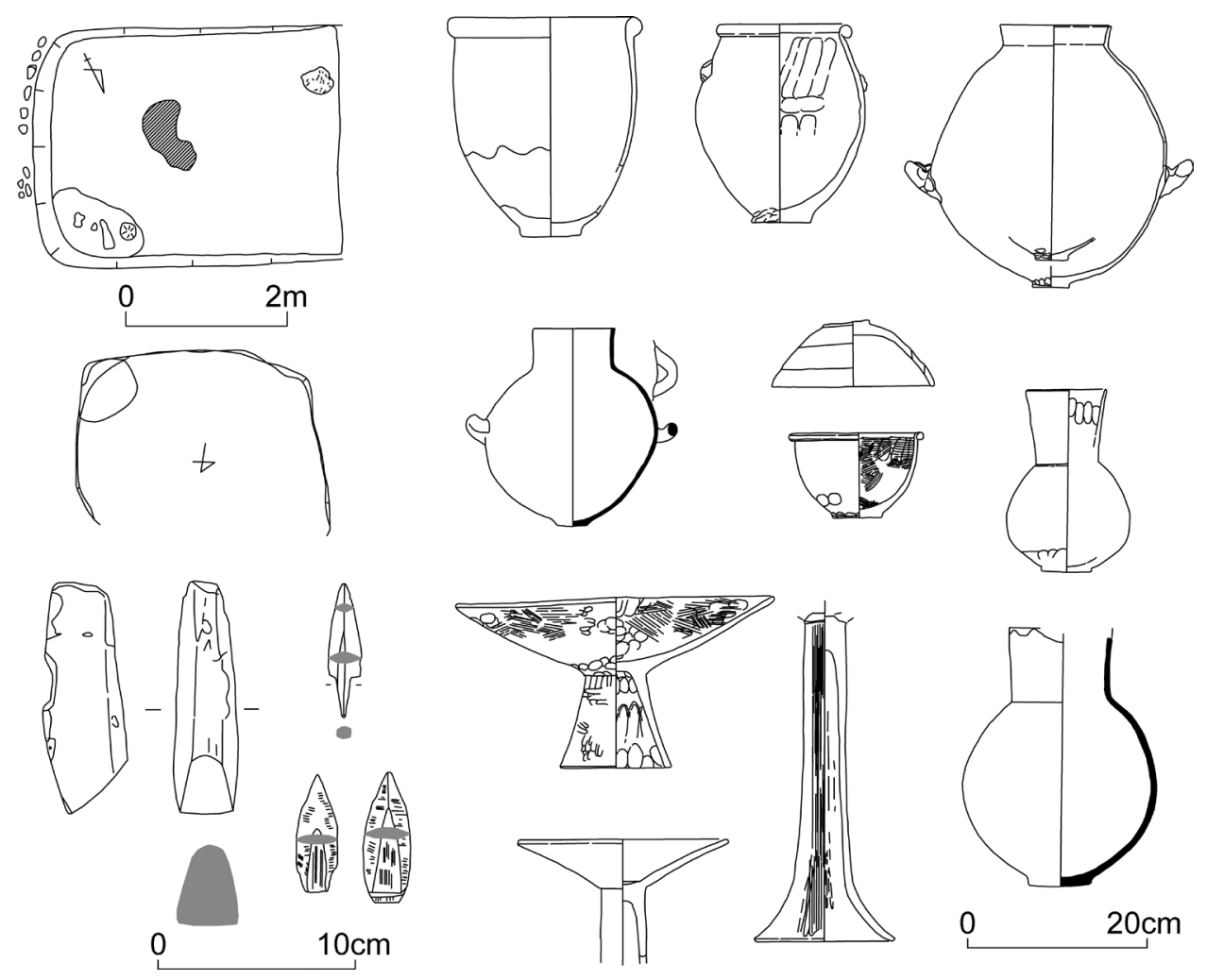

Fig. 8. A Suseok-ri-Gyoseong-ri type assemblage.

wet-rice cultivation (Kim 2003b). However, these attempts at explaining these tenuous links have had only limited success; they remain very hypothetical and are not based on any substantial collection and analysis of data.

Late Bronze Age (LBA) - The LBA (400-150 B.C.E.) can be characterized by the florescence of bronze cultures (Yi 1992b, 1992c) and the influx and spread of Suseokriand Gyosong-ri type assemblages, sometimes called jeomtodae-togi (rolled-rim pottery) assemblages, into central and western parts of the Korean Peninsula (B. Kim 2001; Park 2000; Park 1993b, 1998b) (Figs. 8 and 9).

The LBA bronze culture in this region has sometimes been designated "Korean Style Bronze Dagger Culture" (Yi 1992c). It can be distinguished from Liaoning-type equivalents (seen as prototypes) and includes new items when compared to assemblages from the MBA (Fig. 10). The inclusion of a set of bronze "ritual" artifacts interred in a new style of burial involving stone-filled stone slab tombs has been taken as indicative of sociopolitical changes occurring in this period, specifically: individualization in elite burials (B. Kim 2001), intensification of religious leadership (Kim 1994, 1996), and agglomeration of local small polities (Park 1998a, 1998b).

Unlike the preceding subperiods, the formation of the material culture of the LBA in the central-western Korean Peninsula is generally thought to have started with the adoption and recombination of cultural traits originating outside the peninsula 


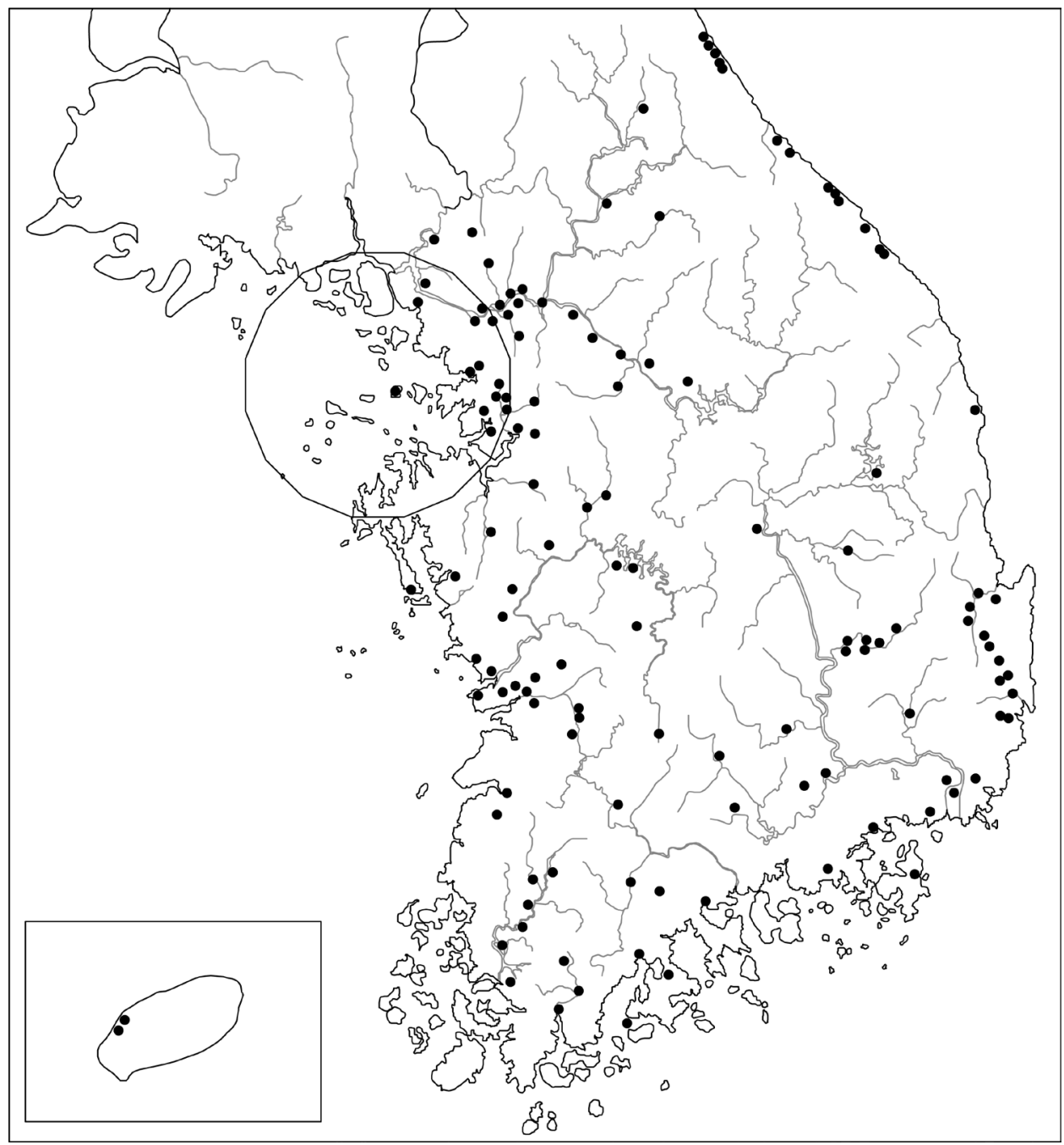

Fig. 9. Distribution of LBA sites. Redrawn and slightly modified after Lim (2009:12).

(B. Kim 2001; Park 1993b, 1998b). The formation and spread of LBA culture in this region is considered closely related to drastically changing sociopolitical circumstances associated with the well-documented development of the so-called Yellow Sea Interaction Sphere. Historical texts of the period demonstrate that the Yellow Sea Interaction Sphere brought the fledgling complex societies of the LBA into sustained contact with polities outside the peninsula during the late Warring States period of China (third century B.C.E.) (B. Kim 2001; Park 1998b).

\section{Socioeconomic Changes in the EBA-MBA Transition: A Brief Introduction}

As mentioned above, the EBA-MBA transition can be characterized by the formation and spread of components of new archaeological culture identifiable with Songguk-ri 


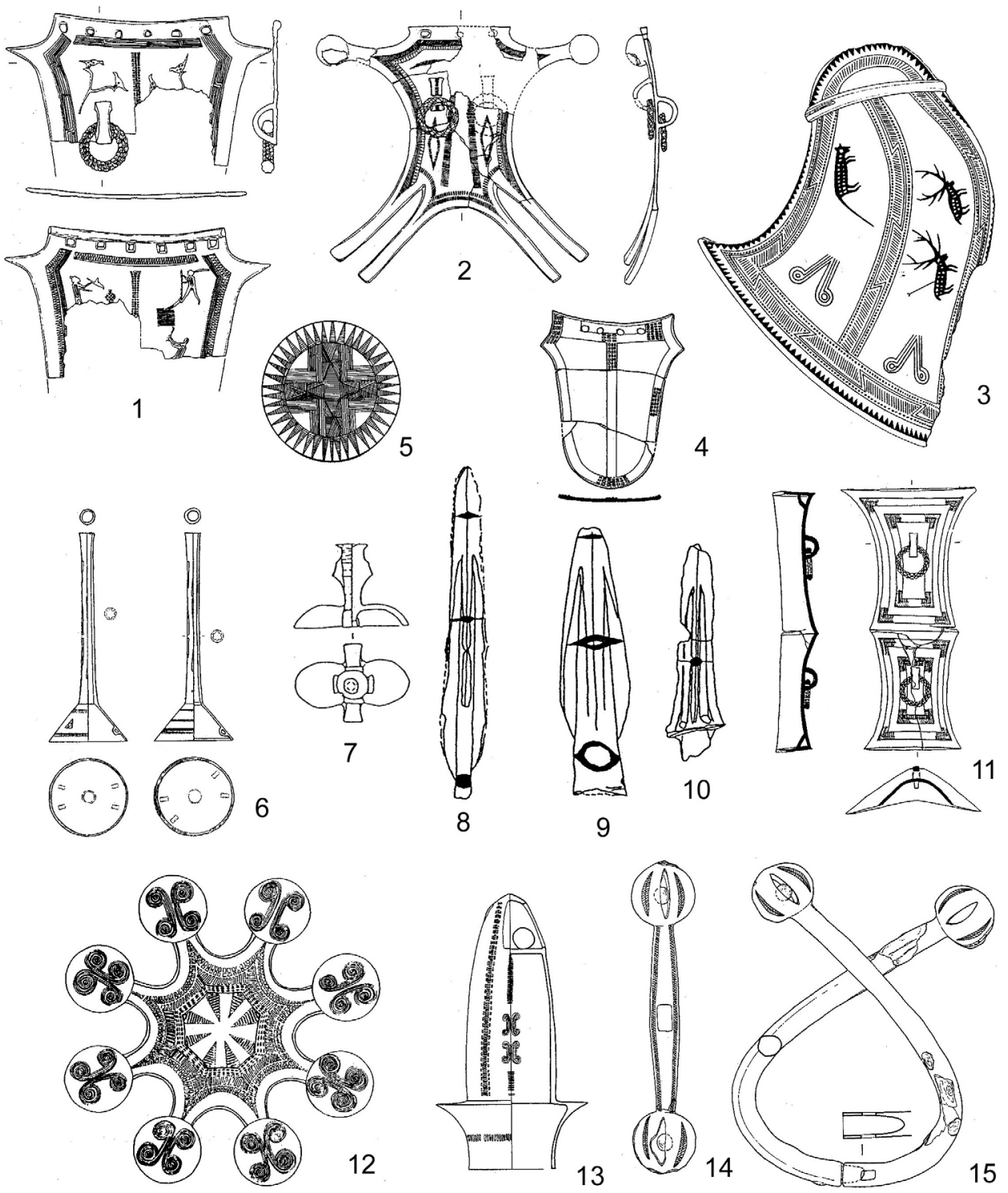

Fig. 10. Assorted bronze artifacts from LBA burials. 1: object with an agricultural motif; 2 and 4: shieldshaped objects; 3: shoulder protector; 5: mirror; 6: trumpet-shaped object; 7: dagger hilt ornament; 8: dagger; 9: halberd; 10: spearhead; 11: sheath ornament; 12: eight-branch bell; 13: stick bell; 14: twoheaded bell; 15: fabricated bell.

type assemblages in the so-called Songguk-ri Culture Area and some local ones outside it.

Regardless of their cultural affiliation, the spread of MBA material culture was accompanied by several kinds of socioeconomic changes, evident in the following: 1) drastic increase in the number and size of habitations and the emergence of large settlements functioning as central places; 2) changes to the internal structure of settle- 
ments (B. Kim 2006a; Kwon 1997); 3) intercommunity functional differentiation (Ahn 2004; Kim 2005); 4) emergence of variability in intra-community wealth or status (B. Kim 2006a); 5) development of defensive works enclosing residential areas of villages and abandonment of houses showing evidence of abrupt burning (Song 1995); 6) mortuary differentiation within and between groups, including the emergence of burials with elaborate and uncommon grave goods assumed to belong to chiefs and structuration in burial placement (Kim 2004); 7) emergence of communal storing facilities (J. Kim 2008a); and 8) building of collective ritual facilities (Lee 2009). These various changes in Korean Bronze Age societies can be grouped into three distinct dimensions: social organization, subsistence intensification and craft specialization, and mortuary and ritual activities. In the following sections, the transformations within the social, economic, and ideological spheres are discussed in more detail.

\section{HOUSEHOLDS, LOCAL COMMUNITIES, AND REGIONAL-LEVEL ENTITIES}

Korean Bronze Age settlement and dwelling patterns have been intensively explored for a long time by archaeologists, since the temporal and spatial dimensions of this period were established by analyzing residential structures and the ceramic vessels and stone tools associated with them. However, attempts at relating physical dwellings or settlements to human social groups such as households, local communities, or regional polities have been less successful. This can be attributed to a lack of familiarity amongst Korean archaeologists with the analytic methodologies and theories embraced in American settlement and household archaeology (Kim 2014a). For example, despite the fact that archaeological surface surveys have been an inevitable starting point of most archaeological projects in Korea, no substantial attempts have been made to reconstruct regional-scale settlement systems by incorporating surfacecollection data with excavation data. Nevertheless, numerous large-scale CRM projects conducted over the last two decades have greatly increased the settlement data available to us. Some projects have almost completely exposed the entire expanse of ancient villages. Furthermore, local governments have sponsored projects to map archaeological sites. These projects have made it possible to draw a broad picture of the distributional patterns of settlements in some regions even without full-coverage surface surveys having been conducted.

\section{Settlement Hierarchy and Intercommunity Differentiation}

A regional-scale reconstruction of the MBA settlement hierarchy in the middle and lower reaches of the Geum River basin was based in part on data accumulation from government-sponsored mapping and CRM projects (Kim 2005). In collecting data and defining components of regional settlement systems, this author adopted the methods devised in American-style regional settlement studies, such as the siteless survey (Dunnell and Dancey 1983; Ebert 1992), systematic surface collection (CICARP 2003), and occupational surface analysis (Peterson and Drennan 2005). This study inspired later research examining various levels of the constituents of settlement systems (i.e., dwellings, clusters of individual dwellings, and whole settlements) and relationships amongst the constituents (J. Kim 2007; Lee 2009; Song 2007). 

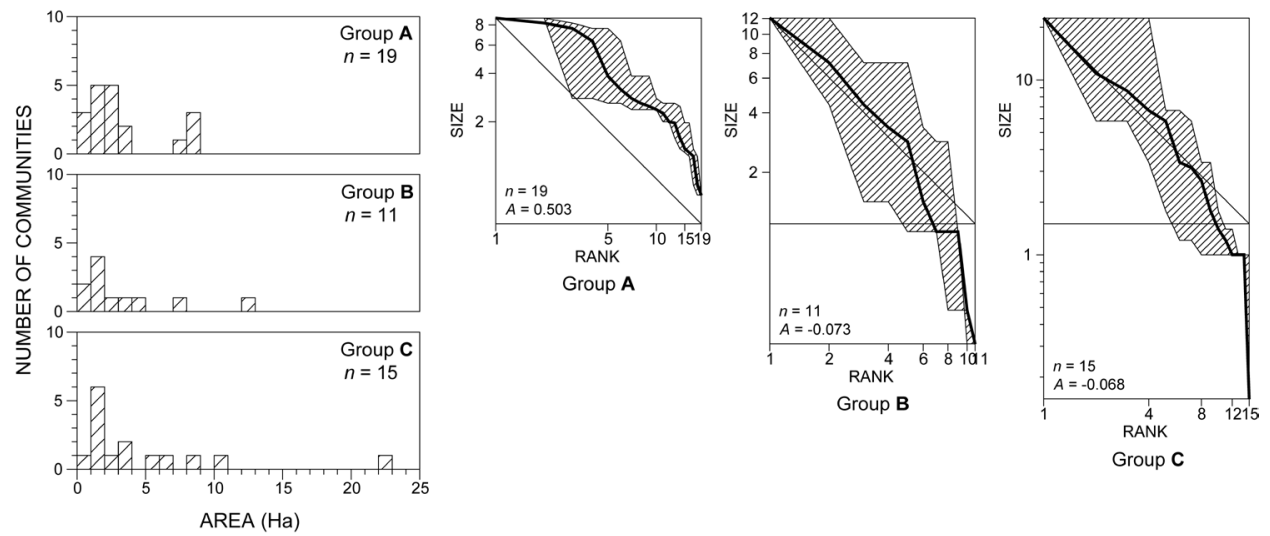

Fig. 11. Histograms and rank-size graphs for three polities in central-western Korea. Redrawn and slightly modified after Kim (2005:20-21).

Research on relational patterns amongst regional settlements first examined large sites taken as focal points of regional settlement systems. Previously unparalleled largescale excavations at various locations resulted in a substantial accumulation of data from large sites. Several large sites such as Songguk-ri in Buyeo, Gwanchang-ri in Boryoung, and Daepyong-ri in Jinju were identified as central places within the regions where Songguk-ri type assemblages have been discovered. The emergence of central places of this kind may also have occurred even outside the Songguk-ri Culture Area, with the sites known as Yongam-dong (in Hwacheon), Jungdo-dong (in Chuncheon), and Sinwha-ri and Gyodong-ri (in Ulsan) being possible cases. Those largehabitation sites might have been positioned at the apexes of settlement hierarchies within the regional polities to which they belonged. Hierarchical systems might have been at least three-tiered (Kim 2005, 2011a) (Fig. 11). In archaeological studies of emergent complexity in other regions of the world, three-tiered systems and primate (or log-normal) rank-size curves have usually been recognized as associated with regionally integrated complex societies (Johnson 1980).

Sites targeted for excavation in Korea have not always been large or central to a settlement system. A lot of smaller sites have instead been recorded around large "central place" settlements. Analysis of the density and size of these smaller sites is also important for determining the nature of the complex societies they represent. Indeed, most Korean Bronze Age specialists currently agree that one of the most salient sociocultural changes inferred from the regional settlement and dwelling patterns of the EBA-MBA transition is the significant increase in both the number and size of habitation sites in conjunction with the emergence of central places. As the body of data has grown, scholars have paid greater attention to relational patterns among settlements of varying sizes and levels in the settlement hierarchy. For example, the relationships between large settlements and other settlements in these systems are expressed in terms of regional networks arranged in a dendritic form (Lee 2009; Minc 2006) (Fig. 12).

\section{Household Reorganization and Intracommunity Variability}

During the EBA-MBA transition, there might have been three lines of critical change in household patterns: structural, relational, and functional (Kim 2012a, 2013). As 

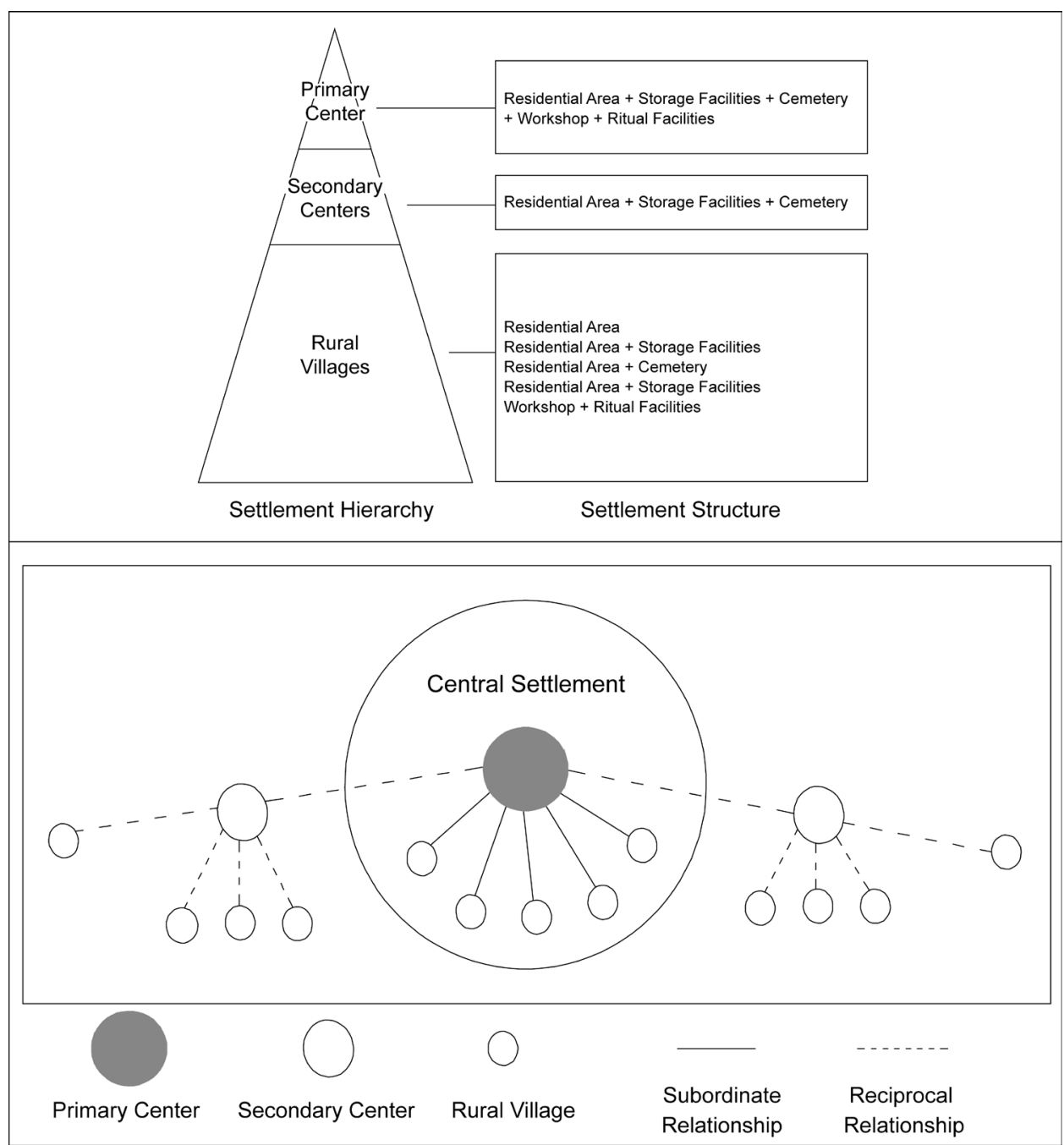

Fig. 12. Schematic network of local communities around a Songguk-ri site. Redrawn and slightly modified after Lee $(2009: 241)$.

mentioned previously, the shape of dwelling structures changed from rectangular to circular or (much less frequently) square. This was accompanied by a remarkable decrease in dwelling size or what may be referred to as residential space. This transformation seems to reflect changes in household size or even household composition. Several studies assume that house form changes are related to changes in family structure such as shifting from extended to nuclear families (Ahn 2006; Kim 2011b; S.-O. Kim 2006; Lee 2009). Although not all members of households would necessarily have been in familial relations, multigenerational families co-reside in single residential structures in many past and present societies; no current evidence indicates that Korean EBA co-residents were not in familial relations. Korean EBA households residing in long, multisectioned, rectangular dwellings therefore could have been extended or stem families (Fig. 13). 


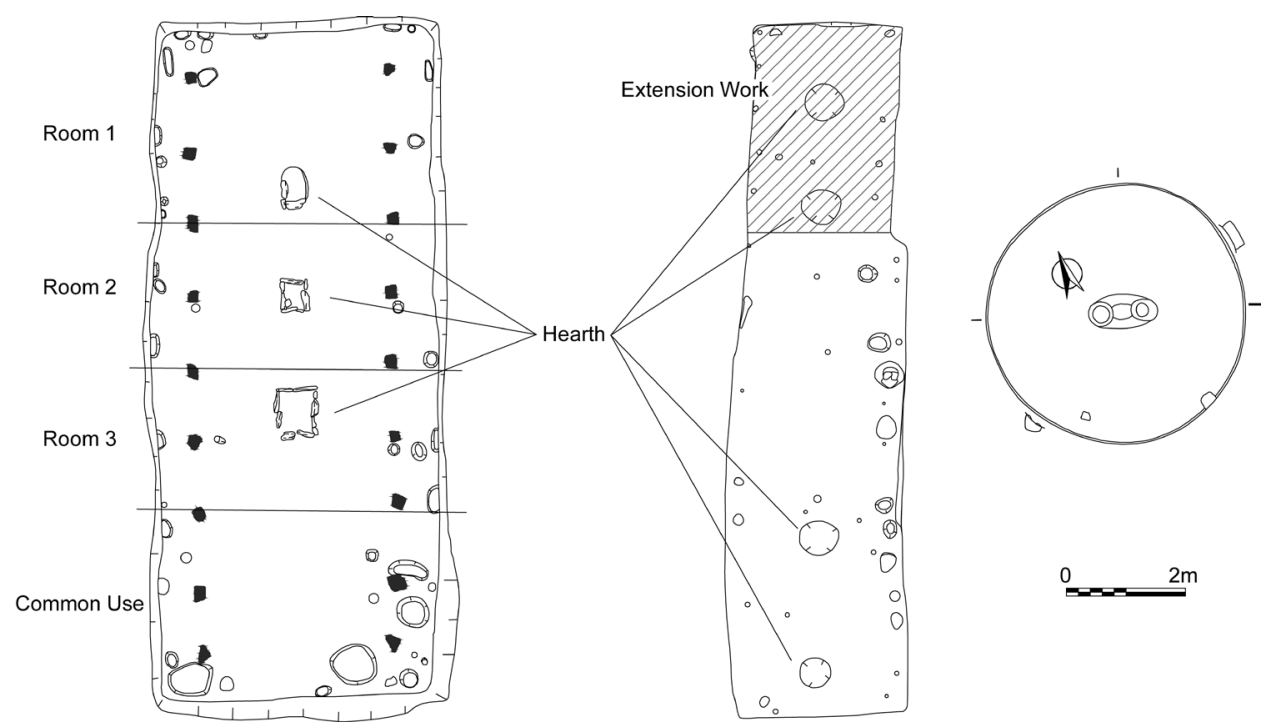

Fig. 13. Comparison of EBA and MBA dwelling structures. Two drawings (left and center) represent EBA long rectangular houses, likely comprised of multiple nuclear families. The drawing on the right is of an MBA round house or Songguk-ri type house.

The phenomenon of changing dwelling structures is not unique to Korean EBA society. Changes in household patterns have been explained by archaeologists using the model of family developmental cycles in the context of Classic Mesoamerica (Haviland 1988; Tourtellot 1988). Despite some possibility of problems arising in relating archaeological patterns to more recent ethnographic models of family structure, it is difficult to deny that attempts at relating dwelling patterns to family relations have produced plausible hypotheses. For example, it is asserted that additive patterns of unitary dwellings constituting long rectangular ones are compatible with archaeological explanations involving the developmental cycle of extended or stem family households. This observation is supported by an analysis of the ratio of long and short axes of individual dwellings from six sites representing substantially long occupation durations in central-western Korea (Kim 2011c, 2012c). The following archaeological implications were inspired by Tourtellot (1988), but modified for the Korean EBA context:

1. The number of unitary dwellings within a household and therefore the long/ short axis ratio increases through generations.

2. Households with longer histories have more units.

3. Single unitary dwellings (a reflection of nuclear family households) are relatively rare, especially at sites of long duration.

4. The majority of dwellings have similar sizes and/or long/short axis ratios.

5. Square or single unitary dwellings should not contain older or a greater number of artifacts than long or short rectangular dwellings.

This model opens up a pathway to elucidating EBA dwelling patterns that have not yet been adequately explained by researchers, such as: Why are single, unitary (traditionally called "square") dwellings in the minority at EBA sites? Should single unitary 
or square dwellings be assumed the most recent type of EBA dwelling? Elsewhere, I argue that the variation in floor shape could have been a function of varying family structure, in which the parental generation and their offspring resided in the same dwelling structure (Kim 2011c). That is, rather than representing a simple stylistic variation with temporal or spatial dimensions, dwellings with different floor shapes (i.e., short, almost square; medium/moderate; or long/extreme rectangles) might represent adaptations to changing numbers of family members occupying the same house over time.

The size of MBA Songguk-ri type dwellings varies, but the mean size of the majority is similar to that of EBA unitary dwellings. For example, the mean size of around 85 percent of MBA dwellings from the central-western region is $15.6 \mathrm{~m}^{2}$, while that of unitary dwellings from the six habitation sites mentioned above is $14.5 \mathrm{~m}^{2}$ (Kim 2012a). Both spaces are suitable for the residence of a single nuclear family household constituted of three or four members (Kim 1968, 1974). The shift in dwelling patterns during the transition from the EBA to the MBA can be interpreted as relating to changes either in household composition or familial structure. If related to familial structure, the shift to a square or unitary dwelling can be interpreted as dissolution of an extended family.

A change in relationship among households can be inferred by observing the distributional patterns of individual dwellings. Clusters of three to five Songguk-ri type dwellings have frequently been observed in MBA settlements. These clusters are often designated "communities of households," that is, alliances of nuclear family households (Ahn 1996; Kwon 1997). Researchers have examined dwelling clusters in EBA settlements ( $\mathrm{Na}$ 2013), but clustering is not as apparent in the EBA as in the MBA. Furthermore, delineations of house clusters in EBA settlements have frequently been suspect and rarely accepted by other scholars (Kim 2014a). Individual clusters at MBA settlements are substantially distinct from each other and therefore easily discernable. The change to clearly delineated house clusters is plausibly explained by the continuum of changes in familial structure or household composition discussed above. The total area of three to five dwellings in an individual cluster is almost equivalent to that of one rectangular EBA dwelling. Thus, a cluster could be interpreted as the habitation of a single but divided extended family household. Even though physical residence became somewhat segregated, familial ties might have been maintained. In other words, the MBA "household cluster" might have functioned as a "pseudo-large household" (Kim 2012a). If each house cluster represents a single pseudo-large household, then distances between households increased greatly in the transition from the EBA to the MBA (Kim 2012a) (Fig. 14).

The structural and relational changes in household patterns just discussed could be explained by drawing on cross-cultural research. According to some ethnographic and archaeological investigations, groups subsisting on intensive agriculture tend to prefer households that are small and relatively distant from one another (Drennan 1988; Wilk and Netting 1984). The hypothesis that changes in both size and distance of households were influenced by changing patterns of production can be supported by analysis of household lithic assemblages. Substantial changes in functional categories of stone tools are apparent, including the increasing presence of carpentry tools, decreasing lumbering tools, and so forth. Considering that wet-rice agricultural tools were mainly made of wood in premodern times, a substantially increased proportion of carpentry tools is likely to indicate even more intensive wet-rice cultivation (Fig. 15). 


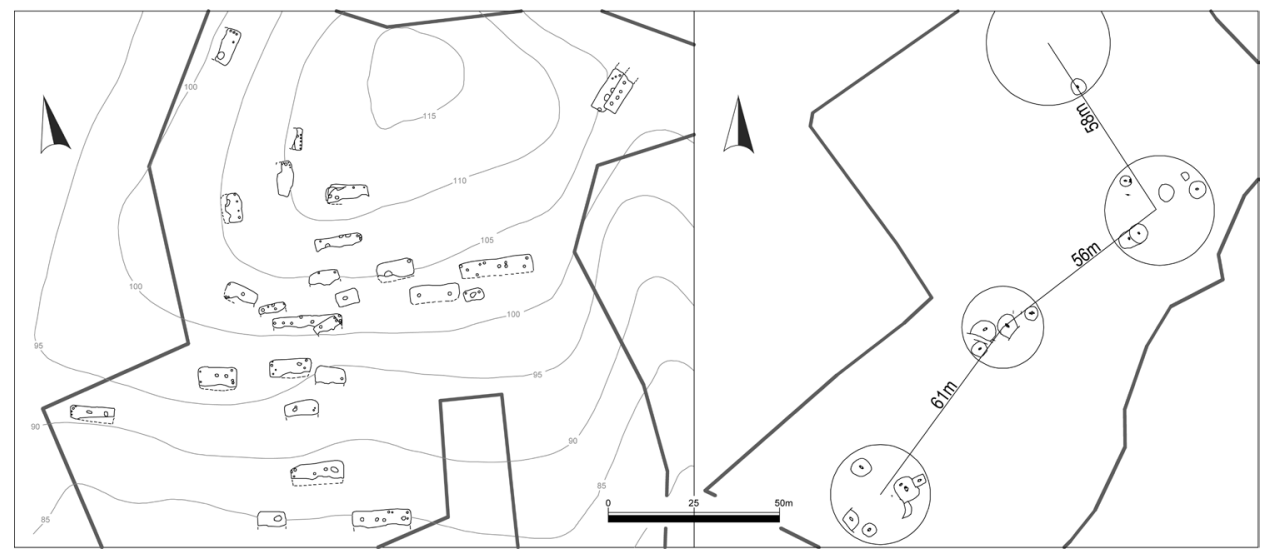

Fig. 14. Comparison of the distributional patterns of EBA (left) and MBA (right) households.

As will be discussed in the next section, wet-rice agriculture is usually viewed as an intensive form of rice cultivation. Structural and relational changes in household patterns can thus reasonably be assumed to have some association with MBA agricultural intensification (Kim 2012a).

A shift in the organization of the agricultural production task unit can also be inferred from changes in the household stone-tool assemblages. Settlements in both periods had almost equal numbers of stone tools per household (Kim 2012a). Considering that the transition witnessed a shift of household composition or familial relations, we suggest that the task unit for agricultural production might have changed from large extended family households to small nuclear family ones. That is, the extended family or pseudo-large household did not necessarily function anymore as the basic unit of agricultural production. This could be seen as a functional change in household patterns and would have resulted from households participating in intensified agricultural practices.

Besides the three lines of evidence for changing household patterns discussed in this section, the EBA-MBA transition witnessed substantial wealth and/or status variability among households within the community. Using the concept of "total wealth" (Smith 1987), a multivariate statistical analysis of dwelling features and artifacts reveals that households with significantly larger dwelling spaces and abundant luxury goods differed from the majority of households in other ways as well. Specifically, the majority of smaller and less wealthy households yielded more tools associated with agricultural production than did the larger, wealthier households (B. Kim 2006a).

\section{AGRICULTURE AND CRAFT PRODUCTION}

Archaeologists broadly agree that the emergence of complex social organization during the EBA-MBA transition was accompanied by the initiation or at least the rapid spread of rice farming in paddy fields (S.-M. Ahn 2000; Cho 2000; B. Kim 2006b, 2006c; NMK 2000; Yi 2001). A growing body of data indicates increasing nutritional dependency on rice during the transition from EBA to MBA. For example, carbonized rice, rice phytoliths, and rice pollen are more frequently identified in MBA resi- 


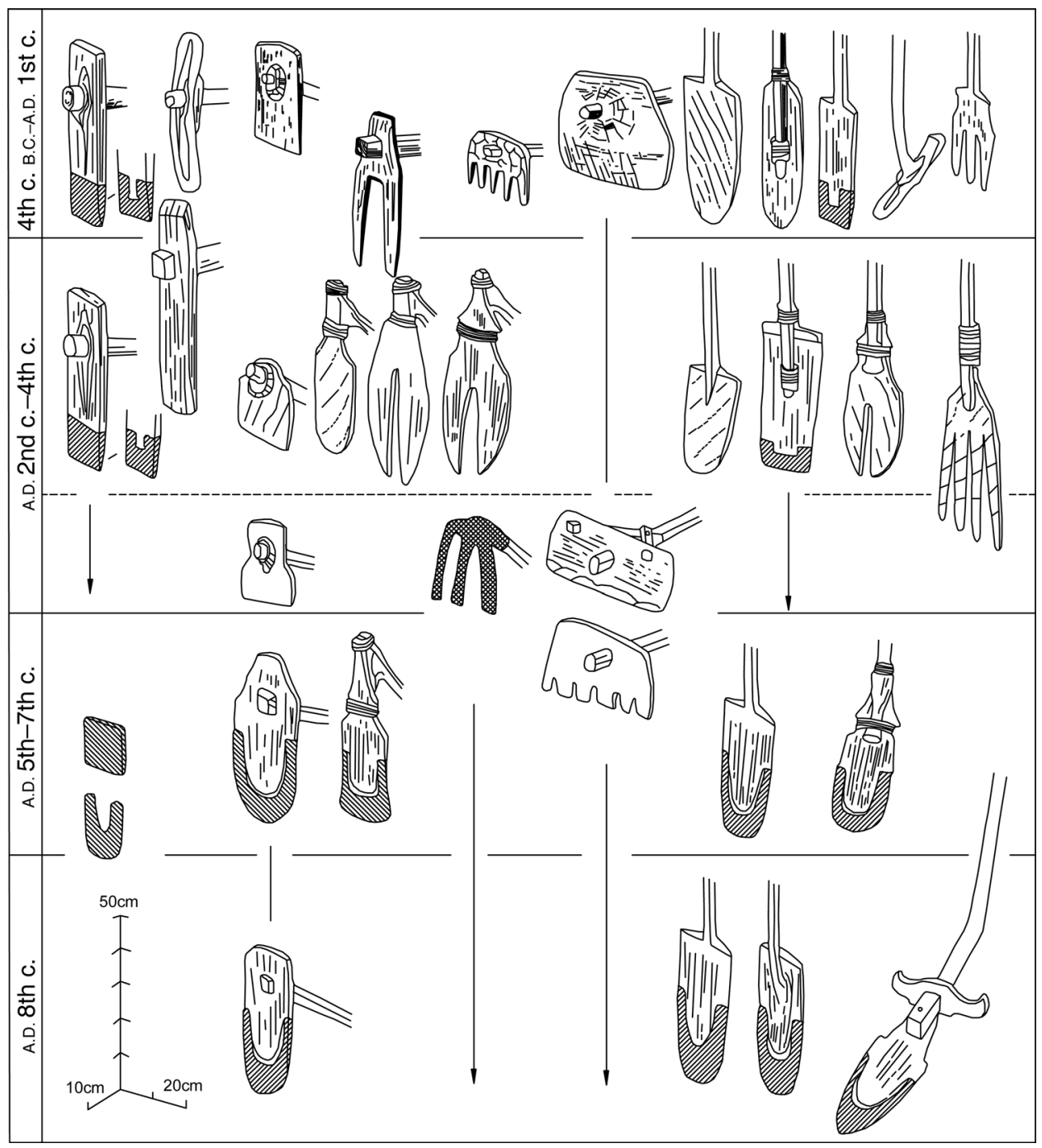

Fig. 15. Ancient wet-rice agricultural tools. This chronological chart indicates the way in which iron blades were added to the original wooden tools. Redrawn after Barnes (1993: 187).

dential areas than in EBA ones (S.-M. Ahn 2000; J.-J. Lee 2001). There is also good evidence for the beginning or acceleration of wet-rice cultivation in central-western Korea during the MBA; actual paddy field plots and related facilities such as ditches and reservoir ponds have been excavated (BRICNNU 2001; Kwak 2001; Lee et al. 2002).

\section{Agricultural Intensification and Regional-Scale Political Economy}

Except for a few suspicious cases, Bronze Age paddies and related facilities are mostly affiliated with the MBA. Found all around central and southern Korea, these paddies likely reflect a vigorous spread of wet-rice production during the MBA. In terms of 
productivity, nutrition, and cuisine, there seems to have been substantial reason for this broad and rapid spread. Rice is very nutritious and highly productive per unit area. Moreover, it is quite palatable and easily transformed into specialty feasting foods (e.g., rice beverages, rice cakes). It appears as a luxury cereal in some East Asian historical documents (Bray 1986; Lee 1992; Ohnuki-Tierney 1995).

Although dry varieties exist, rice is by nature a swamp plant. Continuously higher levels of productivity have been obtained by adopting wet-rice cultivation (Ahn 1999; Bray 1986; Lee 1992). Thus, wet-rice cultivation is inherently a form of agricultural intensification. Rice-farming intensification in the MBA must be understood in the context of centuries of experience in producing and consuming rice, however. Rice was not native to the Korean Peninsula, but it had been cultivated there since the Late Neolithic (S.-M. Ahn 2000; Chi and Ahn 1983; Im 1992, 1997; Kim 1997; G.-A. Lee 2003; Nelson 1999; Norton 2007). Korean MBA peoples were knowledgeable about rice cultivation and its requirements before they began adopting intensive methods of cultivation.

Compared to swidden agriculture, intensive cultivation techniques come at the cost of greater time and labor investments and higher vulnerability to climatic fluctuations. Agricultural intensification is unlikely to have been initiated solely as a solution to subsistence problems generated by drastic population growth, as some have argued. According to this view, agricultural intensification during the EBA-MBA transition is the result of a managerial leadership strategy for meeting the nutritional needs of the majority of the people (J. Kim 2003b). However, the early neoevolutionist paradigm of managerial leadership based on noneconomic factors such as prestige in relatively simple complex societies (Fried 1967; Renfrew 1974; Service 1962) has been challenged (Earle 1977, 1978; Gilman 1981).

Most archaeologists now focus on exploitative leadership strategies in the politicoeconomic domain (Gilman 1981). Elites are seen as trying to monopolize economic infrastructures in order to mobilize surplus to further their own interests (Earle 1978, 1997; Gilman 1981, 1991; Spencer and Redmond 1992). From this perspective, leaders' control over the economic means of subsistence (e.g., arable land, capital-intensive subsistence technology) can be seen as essential to a system of staple finance that enables elites to consolidate political power through the manipulation of fundamental economic resources (D'Altroy and Earle 1985; Earle 1991a; Gilman 1981, 1991). Moreover, the "wealth finance" so important to elites in some societies may rest on the stability of a system of staple finance (Gilman 1991 : 157). In this light, intensifying agricultural production under elite control is an appealing way to generate and enhance elite power for the following reasons: it provides a reliable source of surplus, enabling leaders to fund new political institutions (Arnold 1993; Gilman 1981, 1991; Spencer and Redmond 1992); it creates fixed and easily controlled capital-improvement of agricultural systems, despite the requirement of high initial investment (Gilman 1981); it ties people to the land (Drennan 1988; Pohl 1990); and it protects agricultural facilities against other groups, promoting social solidarity (Gilman 1981; Hastorf 1990).

The relationship between surplus extraction and management of agricultural intensification projects does not seem so simple, however. Considering the lack of efficient tribute systems and truly coercive control over people in chiefdoms (Carneiro 1981), it can be convincingly argued that direct, top-down management of economic production is virtually the only way for elites to obtain a surplus (Delgado- 
Espinoza 2002). Elite-centered models of control that do not contain an element of managerial leadership are thus incomplete.

If elites do not actively manage agricultural production in order to generate a surplus to fund chiefly institutions, they may nevertheless acquire the necessary resources from domestic production by controlling labor (Arnold 1992; Earle 1991b; Johnson and Earle 1987:11-15; Stanish 1994; Webster 1990). Rural households have often been assumed to conform to Chayanov's Rule (Chayanov 1966; Netting 1993), according to which they do not maximize their labor in the absence of political coercion (i.e., a political economy) or environmental risk (Arnold 1992; Halstead and O'Shea 1989; Hayden 1996). When such households are affected by a political economy or incorporation into a market or capitalist economy, they generate surplus by enhancing production beyond subsistence economic demands (Johnson and Earle 2000) and beyond any tax burden placed upon them by supracommunity-level polities (Smith 1987).

Therefore, analyzing distributional patterns of factors suitable for wet-rice production-water sources, soils, and so on-with reference to a regional settlement system could be a plausible way to explore how social components (e.g., regional polities, local communities, and individual households) were related to each other in shaping a specific sociopolitical organization that utilized improved technology for primary agricultural production. In a broad sense, the exploration would be related to current discussion on how agricultural intensification could have been attributed to the development of complex social organization. Recent discussion of the issue shows considerable range of opinion about where to position the societies studied along the continuum ranging from household autonomy in subsistence affairs to direct management of agricultural systems by centralized authorities (Erickson 1993; Scarborough 1991; Stanish 1994). The two ends of this continuum of perspectives on the relationship between sociopolitical organization and intensive agriculture have sometimes been labeled "bottom-up" and "top-down" (Erickson 1993; Scarborough 1991). While a top-down perspective looks at centralized administrative organization, managerial leadership, large-scale labor pooling, and groups of users beyond the household and community level, the bottom-up perspective emphasizes local organization and smallscale facilities that can be handled by single households.

Examining the applicability of models built on the two perspectives in the context of the Bronze Age, central-western Korea shows that a mixture of top-down and bottom-up strategies forms a complementary relationship (B. Kim 2006a). In addition, patterns of the mixture varied among the regional polities. Some primary centers of regional polities represent relatively strong direct elite management of agricultural intensification, while other polities preferred tribute collection and long-distance exchange to focusing on agricultural productivity. Leadership strategies and the preferences of the elite might have contributed to this pattern (B. Kim 2008, 2009). In any case, agricultural intensification during the transition could be considered the first formation of a regional-scale political economy in the central and southern parts of Korea (B. Kim 2006b, 2011a).

\section{Craft Specialization and Symbolic Capital}

Craft specialization in the Bronze Age is a theme that has not been treated enthusiastically in Korean archaeology. However, discussion of the topic has recently become 
active thanks in part to data collected from large-scale excavations in the basins of the Bukhan (North Han) and Nam Rivers.

Songguk-ri type assemblages have not yet been identified in the Bukhan River basin. One of the indicators characterizing the MBA in this area is a square dwelling with a floor hardened with clay. This type of dwelling has been designated a workshop for mundane stone tools (Hong 2009). Dwellings of this kind do not look much different from EBA ones in terms of toolkits and raw materials, however, and it is possible some individuals were devoted to the production of mundane stone tools in the EBA (Cho and Park 2013). That is, specialization cannot be related to the transition if there might have been specialized production of lithic tools in the broadest sense in the Bronze Age. Moreover, this author has elsewhere questioned who the consumers would have been for such mudane tools since so many dwellings belong to this type within each site and a similar pattern has been identified at most sites in the basin (Kim 2014a). Despite these questions, the possibility of community-level specialization cannot be ruled out. At the sites of Gwanchang-ri and Songgruk-ri, for example, we see some evidence that small numbers of households specialized in the production of stone tools or ceramic vessels for the use in the communities to which they belonged (Kim 2011a; Son 2004).

The Nam River basin shows quite different patterns compared to the Bukhan River basin. Analyzing distributional patterns of unfinished objects, raw materials, and tools, Shoda (2009) suggests there may have been specialized production of various beads made of amazonite (called "jade") (Fig. 16). According to Shoda (2009), specialists might have produced such objects for trade within as well as between villages.

Due to their scarcity, beads (whether tubular or comma-shaped) are considered by archaeologists to have been intended as burial goods for the elite dead (Roh 1998). Beads were found in only 8.5 percent of burials at the Daepyong-ri site, which has been singled out as the central place for the Nam River basin. We do not have enough information to conclude if the artisans who participated in specialized bead production could be called "attached," "independent," or "embedded" specialists (Ames 1995 : 158). They are unlikely to have been full-time bead makers, however. Artisans would not have been asked frequently or by many consumers to produce beads. Nevertheless, and more than for any other region in Korea, the finds in the Nam River basin tell us about how craft specialization was related to the production of prestige goods rather than ordinary commodities.

Beads as prestige goods could have constituted "symbolic capital" (Bourdieu 1977:195). Bronze objects, especially Liaoning-type bronze daggers, were more likely salient forms of symbolic capital in the context of the EBA and MBA, however (Kim 2014b; J. Kim 2008a). Although the entire procedure of manufacturing bronze daggers requires some sort of esoteric knowledge, there are no substantial archaeological data indicating exactly how specialized this production was. Based solely on product standardization, it would appear that specialized production of bronze objects emerged in this period (Cho and Lee 2012). However, while it is important to assess production modes, standardization alone is not a necessary and sufficient condition for concluding that specialist production was occurring (Schiffer and Skibo 1997). Nevertheless, it seems clear that items such as beads and bronze objects that are both scarce and highly elaborated could have been used as symbolic capital by would-be chiefs and other elite persons to enhance their sociopolitical grandeur. 


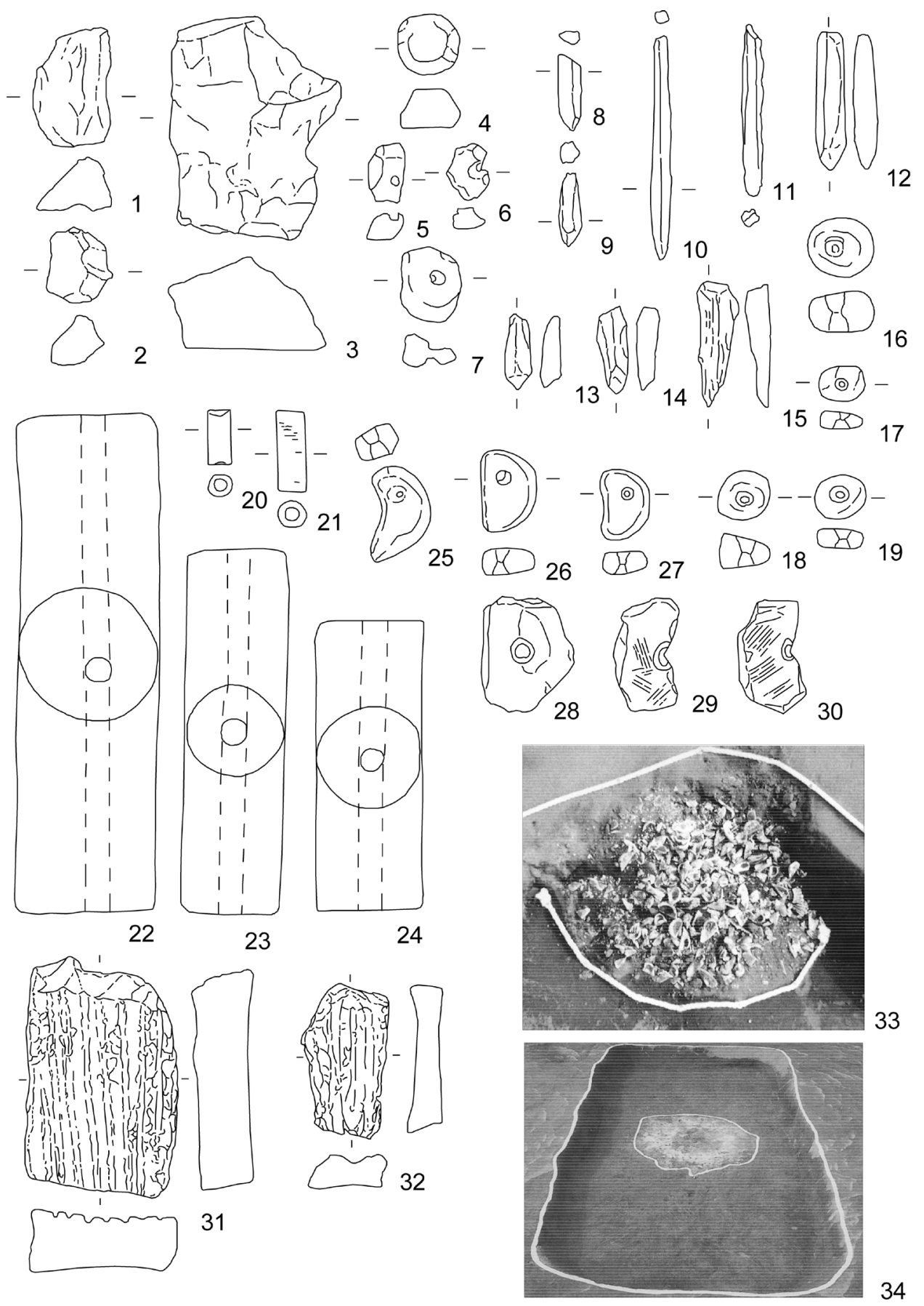

Fig. 16. Raw material (1-3); final products (16-27); unfinished objects (4-7, 28-30); working tools (8-15, 31-32); bead workshops (33-34). Redrawn after Shoda (2009:189). Original figure included photograph 33 (H.-K. Lee 2001 : 792) and photograph 34 (CNRIC $2001: 244$ ). 


\section{MORTUARY PRACTICES AND RITUAL ACTIVITIES}

\section{Mortuary Practices and Social Complexity}

Several types of burials, such as dolmens, stone slab tombs, stone-covered pit tombs, urns, and probably simple pit tombs were used during the Bronze Age in Korea. Archaeological discussion of social complexity based on Bronze Age burial data was begun by a group of scholars whose common primary concern was positioning prehistoric and ancient Korean societies within the framework of American neoevolutionists' typologies of sociopolitical organization.

Dolmens, as megalithic burials, may have been prevalent in Korean Bronze Age landscapes. Dolmens are taken to be elite tombs, the largest of which would have required the expenditure of considerable amounts of energy (Choi 1984; Lee 1980). In addition to metallurgy, they have been pointed to as evidence for the emergence of social complexity (Barnes 1993; Choi 1984; Kim 1986; J.-J. Lee 2001; Nelson 1993). However, this is based on the impressionistic and even simplistic inference that metallurgy and the construction of megalithic tombs required both esoteric knowledge and forms of centralized leadership to organize labor pooling (Choi 1984; Lee 1980). The association of monumental tombs and elite bronze artifacts with rice cultivation is assumed from adaptationalist or functionalist perspectives to indicate the presence of managerial leadership (Brumfiel and Earle 1987), since leaders would have engaged in coordinating the labor pool to construct and maintain paddy fields and irrigation systems (Choi 1984; Kim 1986).

Not all scholars find this reconstruction adequately supported by the evidence. Some critics argue against the notion that the dolmens were elite tombs whose monumentality required a level of energy expenditure adequate to support inferences of institutionalized inequality during the EBA (Kang 1992; Roh 1997; Tainter 1977 :332; O'Shea 1984:17). Their argument is supported by the lack of differentiation in burial goods and that such characteristics of emerging complexity as aggregation of population and differentiation within settlements are rarely seen in the archaeological record of this period (S.-O. Kim 2001). Nevertheless, monumentality cannot be entirely ignored in the discussion of sociopolitical development in the EBA-MBA transition. Building monuments such as dolmens might have been the initial reason for pooling labor at the supra-village level or the dolmens might represent the ideological materialization invested in by elites-to-be in the MBA (Kim 2011b).

Since all burial types (except for dolmens) frequently coexisted within each cemetery in the vicinity of Songguk-ri type habitation sites, they have often been called "Songgukri-type burials" (S.-O. Kim 2001) (Fig. 17). As mentioned before, some Songguk-ri type burials - especially, Songguk-ri Tomb No. 1-have been designated regional chiefs' tombs (Kim 1998). In a similar vein, the Songguk-ri cemetery is considered to be for elite burials, while the Namsan-ri cemetery (a burial site located around $2 \mathrm{~km}$ north of the Songguk-ri site) is for commoners (Kim 1998; S.-O. Kim 2001). The idea that burials were laid out in zonal patterns, separating elite from nonelite cemeteries (Stark and Hall 1993), has been reinforced by observing strong intercemetery but relatively weak intra-cemetery variability (S.-O. Kim 2001).

Bumcheol Kim and Juyoung Park (2012) have challenged this interpretation by denying that mortuary practices did not fall into a zonal pattern during the MBA. They observed that various features of individual burials from both sites intermingle in a group in an MDS graph (Fig. 18). They also find that social rank is not clearly 


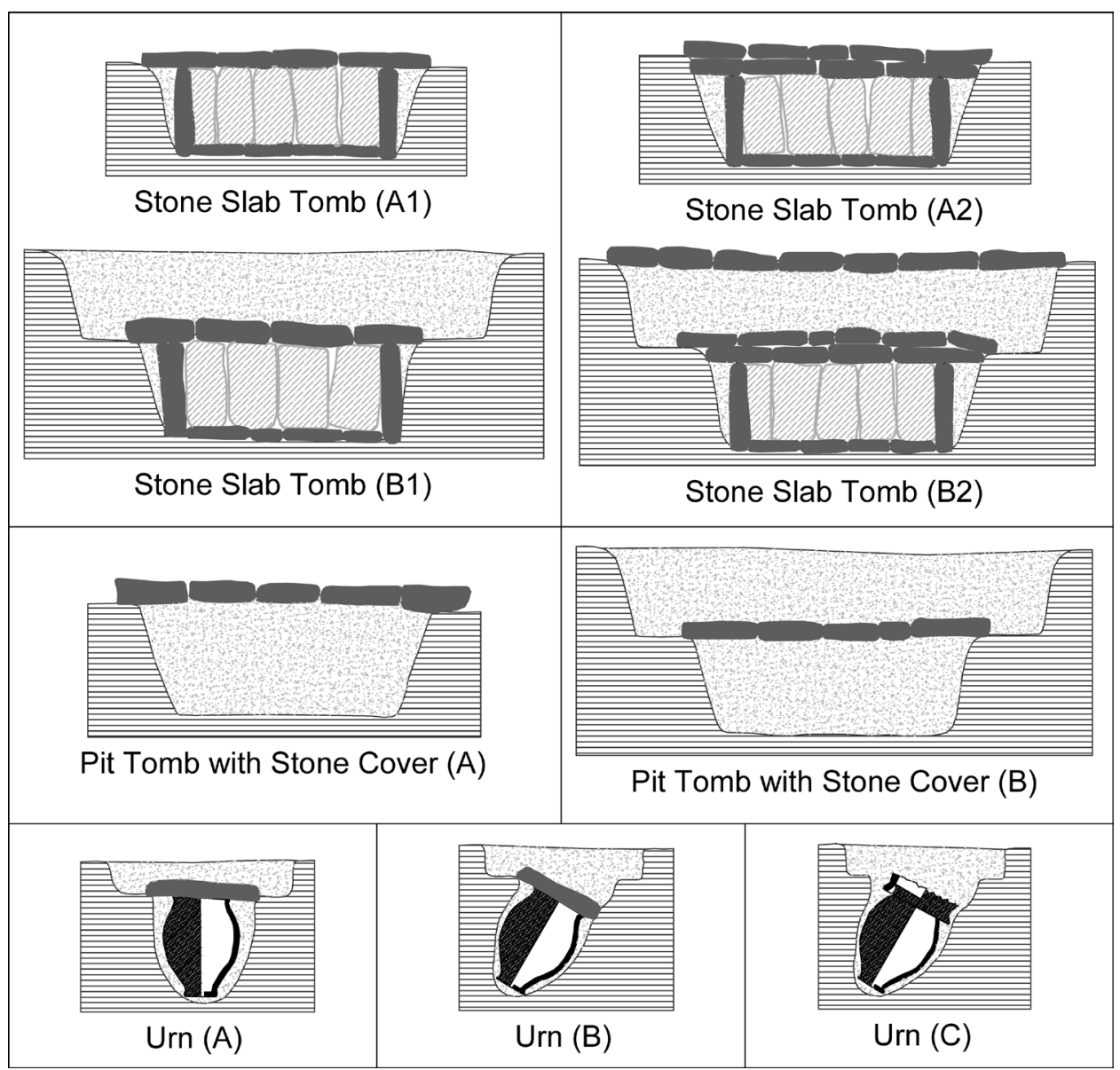

Fig. 17. Songguk-ri type burials. Redrawn and slightly modified after S.-O. Kim (2001:50).

distinguished, at least in mortuary practices, although small numbers of individual burials with abundant and refined burial goods seem to depart from the loosely clustered majority. This tendency for distinction is greater in the centers of regional polities. That is, social hierarchy (as expressed in burial data) is likely to have existed and been more or less continuous among the majority of people in MBA society. As discussed above, this pattern was also identified in the analysis of household wealth/ status variability (B. Kim 2006a). At the regional level, patterns of change shown in both burial and dwelling data during the EBA-MBA transition can be explained as reflecting change in the overarching socioeconomic system that exacerbated differentiation among individuals or households as basic social units.

Observing that groupings in the MDS graphs are generated by the influence of variables representing simple stylistic preferences such as orientation, existence of a bottom pit, or number of tiers in the burial pit, Kim and Park (2012) further suggest that there might have been other rules of social segmentation (i.e., phratry or moiety) besides hierarchical ordering. In short, burial studies should address complex issues 

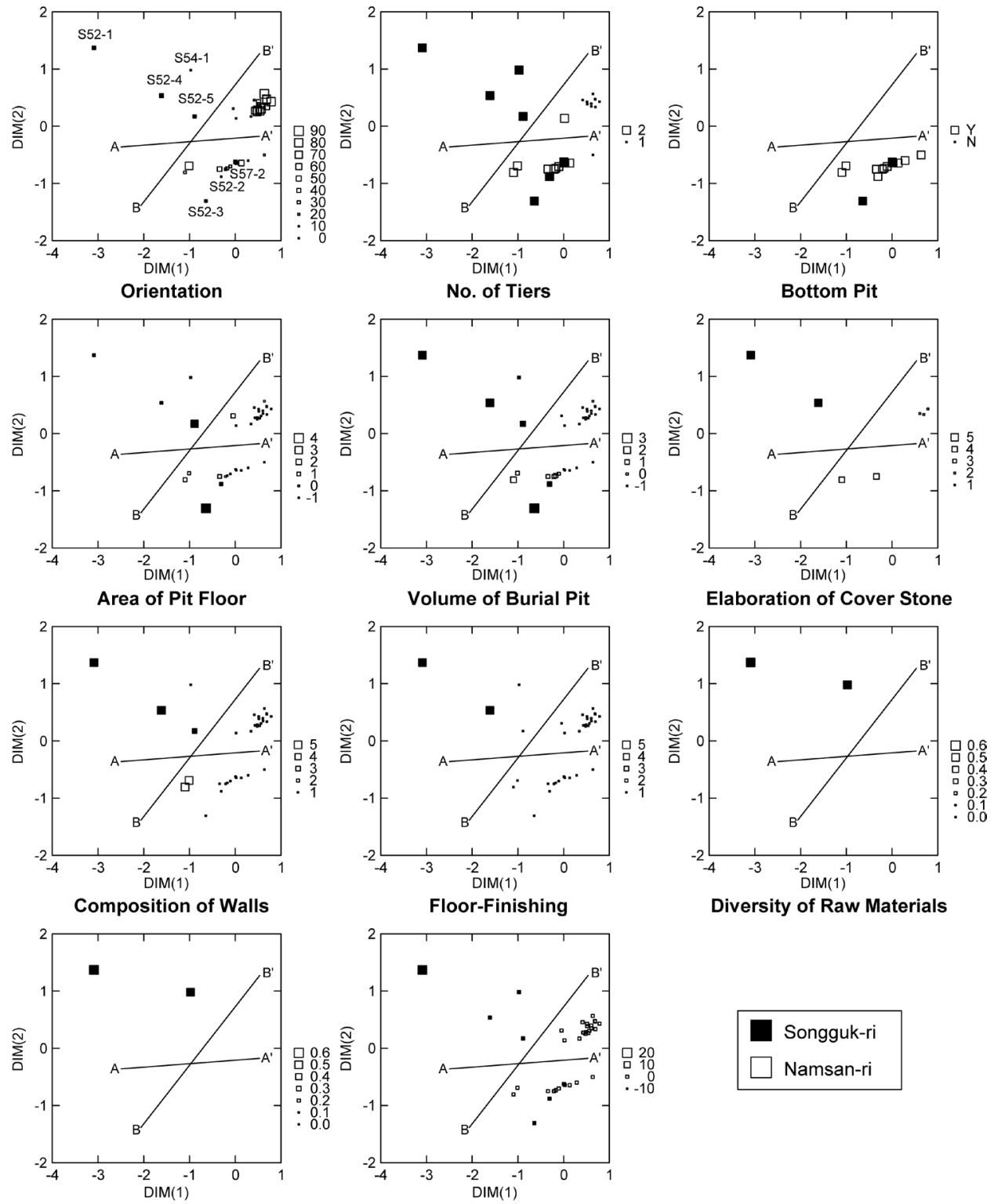

Diversity of Raw Materials

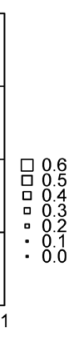

Diversity of Grave Goods

Scarcity Index

Fig. 18. MDS graphs for Songguk-ri and Namsan-ri cemeteries. Redrawn after B. Kim and J. Park (2012:24).

such as the relationship between vertical and horizontal cleavages in social organization, heterarchy, and so on (Kim 2014c).

Collective Ritual Activity and Agricultural Intensification

Many scholars have emphasized the importance of ideological manipulation, sometimes incorporated with economic control by an elite, in the development of complex 
social organization (Earle 1991a). Ideological manipulation can be reflected in how much energy is expended on constructing symbolic monuments such as shrines, burials, statues, and so on (Trigger 1990). Such monumental constructions might have required massive labor pooling and been accompanied by collective rituals. It has been frequently pointed out that the construction of dolmens was closely related to collective rituals and feasts accompanied by supra-community labor pooling (Lee 1993). However, the relationship between the construction of dolmens (as mortuary and symbolic activities) and the enhancement of social complexity has not been systematically modeled.

The systematic modeling should begin with reexamining the temporal dimension of dolmen building. Traditionally, it has been asserted that dolmen building came from China along with plant-cultivating practices during the Late Neolithic. Although it could be agreed that dolmen building was closely related to agriculture, most Korean Bronze Age archaeologists currently associate the appearance of dolmens in Korea with the EBA and MBA. Moreover, some scholars argue that most of the dolmens found in central-western Korea were built during the transition, although some dolmens are dated to the EBA (Kim 2010a). In the southwestern Korean Peninsula, especially South Jeolla Province, which has the densest distribution of dolmens in South Korea, the majority of dolmens date to the MBA (S.-O. Kim 2007). Examining the chronological affiliation of the dolmen burial type brings up new questions: Was the tempo of dolmen construction steady throughout the entire Bronze Age or was it accented by periods of intensive construction? And what caused intensive construction of dolmens throughout the region?

Simply presuming synchronicity between dolmen building and rice cultivation and emphasizing the symbolic role of monumentality in agrarian society is insufficient to explain intensive dolmen construction (Lee 2007; Park 1998a). Intensive construction of dolmens occurred hundreds of years after the agricultural tradition was established in the Korean Peninsula. Moreover, there is no consistent relationship between the distribution of dolmens and factors (i.e., soil and water sources) suitable for wetrice cultivation. Some dolmens were built over almost barren lands for rice cultivation (Kim 2010a). Other explanations for the socioeconomic function of dolmens, such as the territorial model (Chapman 1995; Renfrew 1976) or phenomenological approaches to megaliths (Tilley 1994), were simply adopted from the archaeology of Western Europe, without any substantial analysis of Korean data to support them.

Challenging unicausal models relating social complexity to the dolmen-building tradition, this author suggests taking a more complex, agent-based approach to the issue (Kim 2010b). If dolmens are material expressions of lineage-based collective rituals and mortuary practices, they are therefore of a fundamentally ideological or religious nature. Dolmens have functioned as territorial markers since the EBA. In the EBA-MBA transition, local leaders who pursued sociopolitical aggrandizement might have enthusiastically sponsored dolmen building accompanied by collective rituals. For the leaders, it was taken as the most effective way to monopolize arable land. Arable land could have been the most critical medium for alienating labor from domestic to public spheres. As competition among local leaders heated up, they might have competitively encouraged dolmen building even on previously less occupied areas. Too much competition might have led to unreasonable or erroneous investments in labor and finance by some leaders, but other leaders who made successful investments could have raised their positions to the regional elite. The newly aggrandized elite forced laborers to participate in agricultural intensification (i.e., wet-rice 
farming) in attempts to increase surplus production, which in turn could be used to finance newly established sociopolitical institutions. This would have been the beginning of a regional-scale political economy.

The EBA-MBA transition witnessed remarkable changes in collective rituals. The collective rituals seem to have been brought inside villages. The remains of structures that might have been built on two or three lines of piles-much bigger than the usual posts inside dwellings - have been found at regional-level central places such as Songguk-ri, Gwanchang-ri, and Yigeum-dong (Sacheon); these have been inferred as buildings intended for ritual activities (Lee 2009) (Fig. 19).

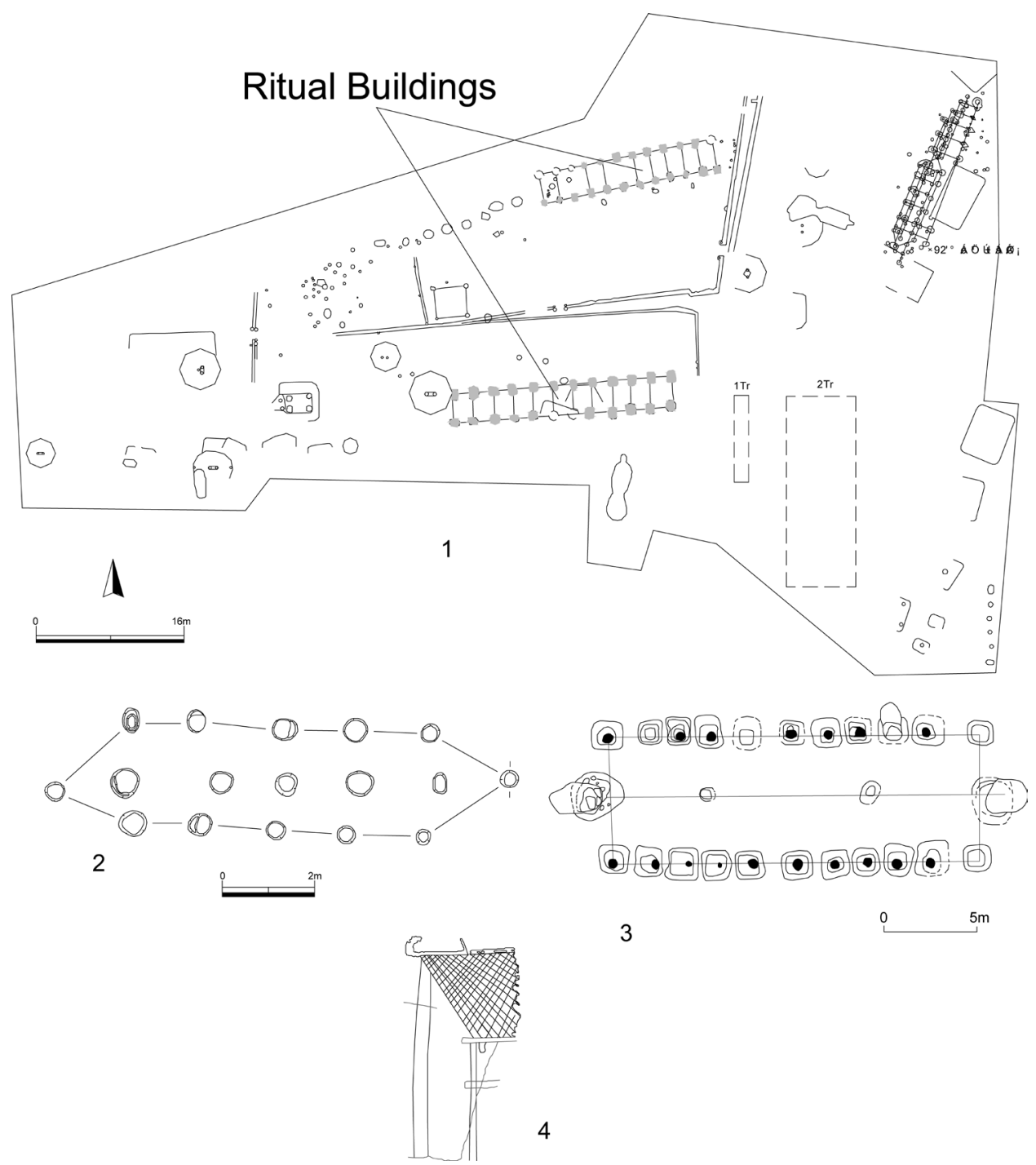

Fig. 19. Ritual buildings indicated by postholes at Songguk-ri site (1); Gwanchang-ri site (2); Ikekamisone site, Japan (3); and a reconstructed feature at Yoshinorga-ri site, Japan (4). 
Since ritual-related facilities came into villages or were located near residential areas, the frequency and importance of collective rituals could have increased. On the other hand, the nature and fundamental purpose of rituals also might have shifted. As mentioned above, rituals accompanying dolmen building were probably linked to mortuary activities. Such rituals may have made it possible for the local leaders who were sponsoring dolmen construction to issue rights to productive land around the dolmens. However, ritual activities that took place inside MBA residential areas might have been performed by members of the work parties (Dietler 2001). Such rituals would have encouraged and compensated commoner households for participating in intensive agricultural work. The abundance of elaborate serving vessels at the centers where top-down strategies in agricultural production were rigorously pursued is likely to have reflected that situation (Kim 2011a). For example, red-burnished pottery is identified much more at Songguk-ri than at any other centers or rural villages in central-western Korea (B. Kim 2006c, 2011a) (Fig. 20).

\section{DISCUSSION AND CONCLUSIONS}

Sociopolitical developments in the central and southern parts of the Korean Peninsula during the EBA-MBA transition might have been closely related to economic intensification. It is not unusual for an elite to exert control over dimensions of the economy; this can be a critical factor in enhancing social complexity. Although empirical data from various parts of the globe show that emerging chiefs depended on various sources of power (Earle 1991a, 1997; Feinman 1995), many scholars consider controlling basic economic resources one of the most important sources of power (Earle 1997; Patterson 1991). To achieve economic control and a monopoly on land capital, elites often attempt ideological manipulation of commoners by holding collective rituals and gain symbolic capital by having monuments built, obtaining prestige goods, and so on (Earle 1997). The formation of a regional-scale political economy in the Korean EBA-MBA transition could be comprehensively explained along the lines of the current theories already mentioned, but the case of the Korean Bronze Age may nevertheless be considered unique.

Rather than focus on minor incompatibilities between general theoretical discourse and the case of the Korean Bronze Age, this article examined the potential for Korean Bronze Age archaeology to contribute to future comparative research. One of the possible contributions could be in discussing relevant issues on the basis of a rigorous analysis of the Korean data set. Korean archaeology has already accumulated data of quite high resolution and density as a result of numerous CRM projects that have been generated as part of a nationwide policy of intensive land development. Such primary data can contribute to comparative analyses on a variety of topics.

One such topic is the relationship between leadership strategies and economic intensification. Various leadership strategies can be divided into two broad groups: managerial versus exploitative. Almost no cases are perfectly compatible with either of these extremes, however. Managing and exploiting should probably not be viewed as a sharp dichotomy, but rather as two ends of a continuum (Shelach 1999). Considering a range of possible strategies that fall in between the two extremes will lead us to pay attention to elites' tactical activities that fundamentally favor intensive production, 

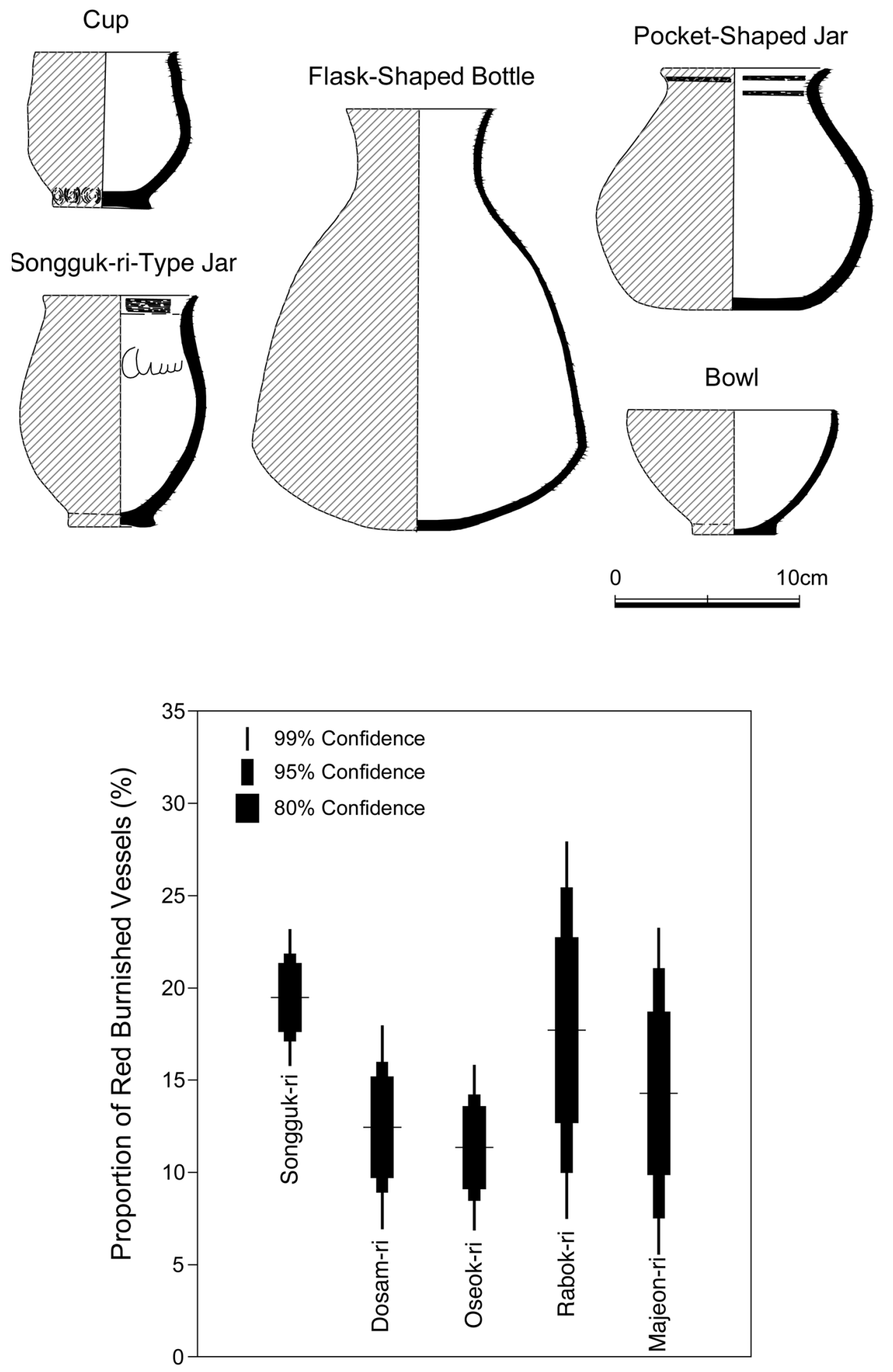

Fig. 20. Elaborate vessels, and comparison of their proportions, from five excavated sites. The sites of Dosam-ri and Rabok-ri represent secondary centers and Oseok-ri and Majeon-ri rural villages in regional settlement hierarchies. 
whether by direct management of intensification projects or by involving commoner producers in such projects with comparatively little coercion. For this purpose, it is important to look closely at how the strategies of elites and non-elites at the household level relate to regional-level, macro-socioeconomic changes. In this vein, I have found it necessary to further develop the concept of "opportunistic" leadership strategies in the Korean context. Opportunistic strategies include elites providing incentives to primary producers to intensify existing technology or elites themselves engaging in restricted agricultural intensification specifically aimed at producing a surplus to fund the political economy (Stanish 1994). Opportunistic strategies may have been favored over managing agricultural production on a broad scale and then collecting tribute to further long-distance exchanges or military activities (Spencer et al. 1994; Spencer and Redmond 1992; Stanish 1994).

Another topic of interest concerns changing household forms. This article discussed various factors that influence household composition and structure. These factors are closely related to several general kinds of household activities: production, distribution or consumption, reproduction, transmission, and so on. However, specific activities always favor the same form of household. Once a discordance of preference happens, there should be some sort of compromise between influential factors. Anticipated by Wilk and Netting (1984), situations where households change as a matter of compromise is a very promising approach to take in household archaeology, but has not been thoroughly explored.

Aside from the two issues just mentioned, there are numerous other problems and hypotheses that could be better understood by including evaluation of Korean Bronze Age data. I anticipate and hope that more hypotheses can be tested using data originating from Korean Bronze Age archaeology.

\section{REFERENCES CITED}

AhN, JAE-Ho

1992 Rethinking Songgukri-type assemblages. Youngnam Archaeological Review 11:1-34. (in Korean with English abstract).

1996 The development of Mumun villages: Establishment of the Middle Mumun Phase on the basis of habitation sites, in Papers in Honor of Retirement of Professor Yoon Yong-Jin: 43-90. Compiled by Committee for Papers in Honor of Retirement of Professor Yoon Yong-Jin. Daegu: Sinheung Printing Works (in Korean).

2000 The formation of agricultural society in Korea. Journal of the Korean Archaeological Society 43: 41-66 (in Korean with English abstract).

2004 A comparison of the Middle Bronze Age settlements. Journal of the Korean Ancient Historical Society 43:1-24 (in Korean with English abstract).

2006 The Study of Settlements of the Bronze Age. Ph.D. diss. Busan National University, Busan (in Korean with English abstract).

Ahn, Sung-Mo

1999 Origin and Differentiation of Domesticated Rice in Asia. Seoul: Hakyounmunhwasa (in Korean).

2000 The beginning and spread of rice agriculture, in Rice Agriculture in Ancient Korea: Proceedings of National Museum of Korea Academic Symposium: 1-20. Seoul: National Museum of Korea (in Korean).

Ames, Kenneth M.

1995 Chiefly power and household production on the Northwest Coast, in Foundations of Social Inequality: 155-187, ed. T. D. Price and G. M. Feinman. New York: Plenum Press.

Arnold, JeAnne E.

1992 Complex hunter-gatherer-fishers of prehistoric California: Chiefs, specialists, and maritime adaptations of the Channel Islands. American Antiquity 57(1):60-84.

1993 Labor and the rise of complex hunter-gatherers. Journal of Anthropological Archaeology 12(1) : 75119. 
BAE, Jin-Sung

2001 A study of the pillar-shaped adze in Korea. Journal of the Korean Archaeological Society 44:19-66 (in Korean with English abstract).

Barnes, Gina LeE

1993 China, Korea and Japan: The Rise of Civilization in East Asia. London: Thames \& Hudson.

Bourdieu, Pierre

1977 Outline of a Theory of Practice. Cambridge: Cambridge University Press.

Bray, FRANCESCA

1986 The Rice Economies: Technology and Development in Asian Societies. Oxford: Blackwell.

BRicnNu (Baekje Research Institute, Chungnam National University)

2001 Construction of the Guryong-Buyeo Highway: Preliminary CRM Report for Public Presentation. Daejeon: Baekje Research Institute, Chungnam National University (in Korean).

Brumfiel, Elizabeth M., and Timothy K. Earle

1987 Specialization, exchange, and complex societies: An introduction, in Specialization, Exchange, and Complex Societies: 1-9, ed. E. M. Brumfiel and T. K. Earle. Cambridge: Cambridge University Press.

Carneiro, Robert L.

1981 The chiefdom as precursor of the state, in The Transition to the Statehood in the New World: 37-79, ed. G. Jones and R. Kautz. Cambridge: Cambridge University Press.

Chapman, Robert

1995 Ten years after: Megaliths, mortuary practices, and the territorial model, in Regional Approaches to Mortuary Analysis: 29-51, ed. L. A. Beck. New York: Plenum Press.

Chayanov, Alexander V.

1966 The Theory of Peasant Economy. Homewood: R. D. Irwin.

Chi, Gon-Gil, And Sung-Mo Ahn

1983 Grain remains and cultivating implements from prehistoric Korean sites. Agriculture in Korea 1:53-108 (in Korean).

Cho, Dae-Youn, and Dong-Hee Lee

2012 An examination of the nature of production specialization of bronze products in the Korean Bronze Age. Journal of the Korean Ancient Historical Society 75 :147-168 (in Korean).

Cho, Dae-Youn, and Seo-Hyeon Park

2013 An examination on the nature of stone-tool production in the central region of the Korean Peninsula in the Bronze Age. Journal of the Hoseo Archaeological Society 28:4-33 (in Korean with English abstract).

Cho, Hyun-JONG

1989 A Study of Songguk-ri Type Pottery. M.A. thesis. Hongik University, Seoul, Korea (in Korean).

2000 The origin and development of wet-rice cultivation, in Culture Change and Culture Contact of Ancient Society in Korea: 3-30, ed. H.-J. Lee. Seoul: Seokyung Munhwasa (in Korean).

Choi, Mong-Lyong

1984 A Study of the Yongsan River Valley Culture: The Rise of Chiefdom Society and State in Ancient Korea. Seoul: Dongsongsa.

CiCARP (Cheifeng International Collaborative Archaeological Research Project)

2003 Regional Archaeology in Eastern Inner Mongolia: Archaeological Exploration. Beijing: Science Press.

CNRich (Changwon National Research Institute of Cultural Heritage)

2001 Prehistoric Site of Locality Eoeun 2 of Daepyong-ri, Jinju. Changwon: Changwon National Research Institute of Cultural Heritage (in Korean).

D’Altroy, Terence N., and Timothy K. Earle

1985 Staple finance, wealth finance, and storage in the Inka political economy. Current Anthropology 26(2): 187-206.

Delgado-Espinoza, Florencio German

2002 Intensive Agriculture and Political Economy in the Yaguachi Chiefdom of the Lower Guayas Basin, Coastal Ecuador. Ph.D. diss. University of Pittsburgh, Pittsburgh, PA. 
DietLer, Michael

2001 Theorizing the feast: Rituals and consumption, commensal politics, and power in African contexts, in Feasts: Archaeological and Ethnographic Perspectives on Food, Politics, and Power: 65-114, ed. M. Dietler and B. Hayden. Washington, D.C.: Smithsonian Institution Press.

DrenNan, Robert D.

1988 Household location and compact versus dispersed settlement, in Household and Community in the Mesoamerican Past: 273-293, ed. R. R. Wilk and W. Ashmore. Albuquerque: University of New Mexico Press.

1992 What is the archaeology of chiefdoms about?, in Metaarchaeology: Reflections by Archaeologists and Philosophers: 53-74, ed. L. E. Embree. Dordrecht: Kluwer Academic Publishers.

2000 Games, players, rules, and circumstances: Looking for understandings of social change at different levels, in Cultural Evolution: Contemporary Viewpoints: 177-196, ed. G. M. Feinman and L. Manzanilla. New York: Kluwer Academic/Plenum Publishers.

Dunnell, Robert C., And William S. Dancey

1983 The siteless survey: A regional scale data collection strategy, in Advances in Archaeological Method and Theory, vol. 6:267-287, ed. M. B. Schiffer. New York: Academic Press.

EARle, Timothy K.

1977 A reappraisal of redistribution: Complex Hawaiian chiefdoms, in Exchange Systems in Prehistory: 213-229, ed. T. K. Earle and J. E. Ericson. New York: Academic Press.

1978 Economic and Social Organization of a Complex Chiefdom: The Halelea District, Kauai, Hawaii. Ann Arbor: Museum of Anthropology, University of Michigan.

1991 The evolution of chiefdoms, in Chiefdoms: Power, Economy, and Ideology: 1-15, ed. T. K. Earle. Cambridge: Cambridge University Press.

$1991 b$ Property rights and the evolution of chiefdoms, in Chiefdoms: Power, Economy, and Ideology: 71-99, ed. T. K. Earle. Cambridge: Cambridge University Press.

1997 How Chiefs Come to Power: The Political Economy in Prehistory. Stanford: Stanford University Press.

EBERT, JAMES I.

1992 Distributional Archaeology. Albuquerque: University of New Mexico Press.

Erickson, Clark L.

1993 The social organization of Prehispanic raised field agriculture in the Lake Titicaca Basin, in Economic Aspects of Water Management in the Prehispanic New World, Research in Economic Anthropology, vol. supplement 7:369-426, ed. V. L. Scarborough and B. L. Isaac. Greenwich: JAI Press.

FeINMAN, Gary M.

1995 The emergence of inequality, in Foundations of Social Inequality: 147-152, ed. T. D. Price and G. M. Feinman. New York: Plenum Press.

Feinman, Gary M., and Jill E. Neitzel

1984 Too many types: An overview of sedentary prestate societies in the Americas. Advances in Archaeological Method and Theory, vol. 7:39-102, ed. M. B. Schiffer. New York: Academic Press.

Fried, MORTON H.

1967 The Evolution of Political Society: An Essay in Political Anthropology. New York: Random House.

Gilman, Antonio

1981 The development of social stratification in Bronze Age Europe. Current Anthropology 22(1): 1-23.

1991 Trajectories toward social complexity in the later prehistory of the Mediterranean, in Chiefdoms: Power, Economy, and Ideology: 146-168, ed. T. K. Earle. Cambridge: Cambridge University Press.

Halstead, Paul, and John O’Shea

1989 Introduction: Cultural responses to risk and uncertainty, in Bad Year Economics: Cultural Responses to Risk and Uncertainty: 1-7, ed. P. Halstead and J. O'Shea. Cambridge: Cambridge University Press.

Hastorf, Christine AnN

1990 One path to the heights: Negotiating political inequality in the Sausa of Peru, in The Evolution of Political Systems: Sociopolitics in Small-Scale Sedentary Societies: 146-176, ed. S. Upham. Cambridge: Cambridge University Press. 
Haviland, William A.

1988 Musical hammocks at Tikal: Problems of reconstructing household composition, in Household and Community in the Mesoamerican Past: 121-134, ed. R. R. Wilk and W. Ashmore. Albuquerque: University of New Mexico Press.

HAYDEN, BRIAN

1996 Thresholds of power in emergent complex societies, in Emergent Complexity: The Evolution of Intermediate Societies: 50-58, ed. J. E. Arnold. Ann Arbor: International Monographs in Prehistory.

HNUM (Hannam University Museum)

2003 Daecheonri Neolithic Site, Okcheon. Daejeon: Hannam University Museum.

Hong, JoO-HeE

2009 Development of the Bronze Age community in the North Han River Basin and the establishment of stoneware production system. Journal of the Society for Korean Bronze Culture 5:4-35.

IM, HYO-JAI

1992 Prehistoric rice agriculture in Korea, in Pacific Northeast Asia in Prehistory: Hunter-FisherGatherers, Farmers, and Sociopolitical Elites: 157-160, ed. M. C. Aikens and S. N. Rhee. Pullman: Washington State University Press.

1997 Chronology of the Neolithic, in Palaeolithic and Neolithic Cultures: Korean History, vol. 1:305315, ed. National Institute of Korean History. Gwacheon: National Institute of Korean History (in Korean).

Johnson, Allen W., and Timothy K. Earle

1987 The Evolution of Human Societies: From Foraging Group to Agrarian State. Stanford: Stanford University Press.

2000 The Evolution of Human Societies: From Foraging Group to Agrarian State, 2nd ed. Stanford: Stanford University Press.

JohnSOn, Gregory A.

1980 Rank-size convexity and system integration: A view from archaeology. Economic Geography $56(3): 234-247$.

KANG, BONG-WON

1992 Reexamination of Korean megalithic tombs and social organization. Paper presented at the 57th Annual Meeting of the Society for American Archaeology in Pittsburgh, Pennsylvania.

Kim, BumCHEOL

2001 A study of Late Mumun society in southern Korea: Suggestions for future research in the Seoul region. The Journal of Seoul Studies 16:1-44 (in Korean with English abstract).

2005 Middle Bronze Age regional settlement patterns in the middle and lower reaches of the Geum River. Journal of the Korean Archaeological Society 57:99-124 (in Korean with English abstract).

$2006 a$ Household archaeology of Songgukri-type settlements in the lower and middle reaches of the Geum River: Analysis of household wealth/status variability using MDS. Journal of the Korean Ancient Historical Society 51:79-107 (in Korean with English abstract).

$2006 b$ The political economy of wet-rice production in the Bronze Age, central-western Korea: MBA hierarchical settlement patterns and rice agricultural in the middle and lower reaches of the Geum River. Journal of the Korean Archaeological Society 58:40-65 (in Korean with English abstract).

2006c Political versus subsistence economy of Songguk-ri Culture in Chungnam Province. Journal of the Honam Archaeological Society 24:65-96 (in Korean with English abstract).

2008 Opportunistic leadership and moving people: Political economy and population reorganization in the Bronze Age, central-western Korea. Paper presented at the 73rd Annual Meeting of Society for American Archaeology, Vancouver, BC, Canada, March 23-28, 2008. Abstract $15: 308$ available at: http://www.saa.org/Portals/0/SAA/Meetings/2008\%20Abstracts/ Abstracts2008.pdf

2009 Prehistoric agricultural intensification and opportunistic elite strategy: Rice agricultural intensification and socioeconomic development in the Middle Bronze Age, central-western Korea, in International Conference in Commemoration of Launching the Research Center for Humanities: The Beginning of Civilization and Its Mutual Cooperation, 25 September, Jeonju, Korea: 30-36. Jeonju: Research Center for Humanities, Jeonbuk National University (in Korean with English abstract).

$2010 a$ The temporality and spatiality of Hoseo region dolmens. Journal of the Korean Archaeological Society 74:46-75 (in Korean with English abstract). 
$2010 b$ Socioeconomic function of Hoseo region dolmens. Journal of the Korean Ancient Historical Society 68:5-24 (in Korean with English abstract).

2011a The Archaeology of Rice: Rice Agricultural Intensification and Political Economy in the Korean Bronze Age. Seoul: Minsokwon (in Korean).

$2011 b$ Overheated competition and erroneous investment: Monumentality and political economy in the Bronze Age, central-western Korea. Paper presented at the 76th Annual Meeting of Society for American Archaeology, Sacramento, CA, March 30-April 3, 2011. Abstract 149:176-177 available at: http://www.saa.org/Portals/0/SAA/Meetings/2011\%20Abstracts/ I_L.pdf

2011c Dwelling patterns and household developmental cycle during the Early Bronze Age: With special reference to Yeoksamdong- and Heunam-ri type settlements of the Hoseo region. Journal of the Korean Ancient Historical Society 68:31-60 (in Korean with English abstract).

2011d Comparing the chiefly societies of Northeast Asia. Journal of Northeast Asian History 33:251301 (in Korean with English abstract).

$2012 a$ Some socioeconomic aspect of changes in household patterns in the Bronze Age, centralwestern Korea. Journal of Korean Ancient Historical Society 76:27-49 (in Korean with English abstract).

$2012 b$ Archaeological understanding on megalithic monuments and sociopolitical development: Modeling social roles of dolmens in South Korea. Journal of the Korean Ancient Historical Society 75:57-74 (in Korean with English abstract).

2012c Understanding the variability of rectangular dwellings in the Early Bronze Age, centralwestern Korea. Paper presented at the 5th World Conference of Society for East Asian Archaeology, Fukuoka, Japan, June 6-10, 2012.

2013 The Larger, the safer?: Understanding changes in household patterns in the transition of Early to Middle Bronze Ages, central-western Korea. Paper presented at the 78th Annual Meeting of Society for American Archaeology, Honolulu, HI, April 3-7, 2013. Abstract 22 : 232 available at: http://www.saa.org/Portals/0/SAA/Meetings/2013\%20Abstracts/I-L.pdf

2014 a From "dwellings" to "residences": A proposition for household archaeology in Korean prehistory. Journal of the Korean Archaeological Society 90:164-193 (in Korean with English abstract).

$2014 b$ Understanding changes of domestic storage patterns in the Bronze Age, Hoseo region. Journal of the Korean Ancient Historical Society 83:53-68 (in Korean with English abstract).

2014c Hierarchy, heterarchy and individuals: Middle Bronze Age intra-community mortuary practices in the central-western Korea. Paper presented at the 6th World Conference of Society for East Asian Archaeology, 6-10 June, Ulanbataar, Mongolia.

Kim, Bumcheol, and Juyoung Park

2012 Discussing the hierarchical aspects of Songguri-type burials in the Hoseo region. Journal of the Korean Archaeological Society 82:4-43 (in Korean with English abstract).

KIM, GIL-SIK

1998 The Mumun period tombs at the Songgukni Site, Buyeo. Journal of the Institute of Korean Archaeology and Art History 9:5-49 (in Korean).

KIM, HAN-SIK

2002 A study on Songguk-ri type dwellings in southern part of Korea. Journal of the Hoseo Archaeological Society 6-7:105-139 (in Korean with English abstract).

Kim, JANGSUK

2001 Reconsidering Heunam-ri assemblages: Origin and date. Youngnam Archaeological Review 28:35-64 (in Korean with English abstract).

2002 The Late Neolithic-Early Bronze Age transition in South Korea: A new hypothesis. Journal of the Korean Archaeological Society 48:93-132 (in Korean with English abstract).

$2003 a$ Land-use conflict and the rate of the transition to agricultural economy: A comparative study of southern Scandinavia and central-western Korea. Journal of Archaeological Method and Theory $10(3): 277-321$.

$2003 \mathrm{~b}$ The development of the Songguk-ri assemblage in the Chungcheong area. Journal of the Korean Archaeological Society 51:33-55 (in Korean with English abstract).

2007 Settlement and social complexity studies of the Korean Bronze Age. Journal of the Hoseo Archaeological Society 17:4-25 (in Korean with English abstract).

2008 S Socioeconomic implications of storage facilities of the Songguk-ri period. Journal of the Korean Archaeological Society 67:4-39 (in Korean with English abstract).

$2008 b$ Reconsidering the Incipient Mumun model. Journal of the Korean Archaeological Society 69:94-115 (in Korean with English abstract).

KIM, JEONG-BAE

1979 A study of the origin of Korean Bronze culture. Komunhwa 17:12-22 (in Korean). 
Kim, JeONG-Gi

1968 A study on the Korean subterranean dwellings 1. Archaeology 1:31-60 (in Korean).

1974 A study on the Korean subterranean dwellings 2. Archaeology 3:21-50 (in Korean).

Kim, JeONG-HeE

1997 A New Study on the Prehistoric Rice Agriculture in Korea: With Special Reference to PlantOpal Analysis of Rice Remains in Pottery Vessels from the Han River Basin. M.A. thesis. Chungbuk National University, Cheongju, Korea (in Korean with English abstract).

KIM, JONG-IL

1994 Distributional patterns of bronze objects: With reference to ritual territoriality in centralwestern Korea. The History of Korea 30:1-71 (in Korean with English abstract).

1996 Individuals, Communities and Bronze: A Comparative Study of the Early Bronze Age of Central Europe and Korean Bronze Age. M.A. thesis. University of Cambridge, UK.

2004 An archaeology of death: Interpreting the spatial structure of burial groups in the Songgungni culture of the Korean Bronze Age. Seoul Journal of Korean Studies 15:101-128 (in Korean).

Kim, Seung-Og

2001 A study of the Songgungni-type burials in the Kumgang River Basin. Journal of the Korean Archaeological Society 45:45-73 (in Korean with English abstract).

2006 Chronology and social changes of dwellings in the Korean Bronze Age. Journal of the Korean Archaeological Society 60:4-37 (in Korean with English abstract).

2007 Social organization and its transformation in the Bronze Age on the basis of burial data, in The Emergence of Ranked Society and Chiefs: 61-139. Seoul: Sahoipyoungron and The Korean Archaeological Society (in Korean).

KIM, WON-YONG

1986 Introduction to Korean Archaeology. Seoul: Ilchisa (in Korean).

Kim, Young-Bae, And Seung-Joo Ahn

1975 Stone slab tomb with Liaoning-type bronze dagger at Songguk-ri, Buyeo. Baekje Culture 7-8:7-29 (in Korean).

Ko, ILHONG

2010 Reconsidering Early Bronze Age farming strategies. Journal of the Korean Ancient Historical Society $67: 25-44$ (in Korean with English abstract).

KWAK, JONG-CHEOL

2001 Prehistoric and ancient paddy and dry-field plots in Korea, in Various Issues in Agriculture: Proceedings of 25th Annual Meeting of the Korean Archaeological Society, 2-3 November, Busan, Korea: 21-73. Busan: Korean Archaeological Society (in Korean).

Kwon, OH-Young

1997 Settlements and residence in ancient Korea. Research in Korean Ancient History 12:45-73 (in Korean).

LEE, BAEK-GYU

1974 Mumun and ground stone tools in Gyunggido. Archaeology 3:23-67 (in Korean).

LeE, Chun-Nyung

1992 Rice and Culture. Seoul: Seoul National University Press (in Korean).

LeE, Gyoung-Ah

2003 Changes in Subsistence Systems in Southern Korea from the Chulmun to Mumun Periods: Archaeobotanical Investigation. Ph.D. diss. University of Toronto, Ontario, Canada.

Lee, Hong-Jong, Joon-Ho Son, And Won-Pyo Kang

2002 Majeonni Site: Locality A. Yeongi: Research Institute for Archaeological Resource, Korea University (in Korean).

Lee, Hyeong-Koo

2001 Report of the Archaeological Site at Ok-Bang \#5 in Daepyong-ri. Cheonan: Sun Moon University (in Korean).

LeE, Hyung-Won

2009 Bronze Age Settlement Structure and Social Organization. Seoul: Seogyongmunhwasa (in Korean).

LEE, JIN-MiN

2003 The Study of the Early and Middle Mumun-Pottery Cultures in Central Korea: The Relationship between Yeoksamdong/Garakdong Assemblages and Songgungni Assemblage. M.A. thesis. Seoul National University, Seoul, Korea (in Korean with English abstract). 
LEE, JUNE-JEONG

2001 From Shellfish Gathering to Agriculture in Prehistoric Korea: The Chulmun to Mumun Transition. Ph.D. diss. University of Wisconsin-Madison.

LeE, SOO-Hong

2012 Archaeological Study of Kumdan-ri Type in the Bronze Age. Ph.D. diss. Busan National University, Busan (in Korean with English abstract).

LeE, Sung-Joo

2007 Discussion on the Social Transformation in the Bronze and Iron Ages. Seoul: Hakyounmunhwasa (in Korean).

Lee, Young-Mun

1993 A Study of the Dolmen Society in Chonnam Province. Ph.D. diss. Korea National University of Education, Cheongju (in Korean).

LeE, Yung-Jo

1980 A study on the dolmen culture at Angdeokri, Yangpyong, in A Study of Korean Prehistory: 147-210, ed. Y.-J. Lee. Seoul: Pyongminsa (in Korean).

Lim, Sul-Hee

2009 Study on Clay-Stripe Pottery of Korea: Typology and Temporal Changes. M.A. thesis. Jeonnam National University, Gwangju, Korea (in Korean with English abstract).

Minc, Leah D.

2006 Monitoring regional market systems in prehistory: Models, methods, and metrics. Journal of Anthropological Archaeology 25(1): 82-116.

NA, GEON-JOO

2013 Bronze Age of Sejong City, in Past, Now, and Future of Sejong City: Proceedings of the 27th Conference of Society for Hoseo Archaeology, 3 May, Sejong, Korea: 31-55. Sejong: Hoseo Archaeological Society (in Korean).

Nelson, Sarah Milledge

1993 The Archaeology of Korea. Cambridge: Cambridge University Press.

1999 Megalithic monuments and the introduction of rice into Korea, in The Prehistory of Food: Appetites for Change: 147-165, ed. C. Gosden and J. G. Hather. London: Routledge.

NetTing, Robert McC.

1993 Peasant farming and the Chayanov Model, in Smallholders, Householders: Farm Families and the Ecology of Intensive, Sustainable Agriculture: 259-391. Stanford: Stanford University Press.

NMK (National Museum of Korea)

2000 New Millennium Special Exhibition: Rice in Korean History. Seoul: The National Museum of Korea (in Korean).

Norton, Christopher John

2000 Subsistence change at Konam-ri: Implications for the advent of rice agriculture in Korea. Journal of Anthropological Research 56:325-348.

2007 Sedentism, territorial circumscription, and the increased use of plant domesticates across Neolithic-Bronze Age Korea. Asian Perspectives 46(1) : 133-165.

OHNUKi-Tierney, EMiko

1995 Structure, event and historical metaphor: Rice and identities in Japanese history. Journal of the Royal Anthropological Institute 1(2): 227-253.

O'SHeA, JOHN M.

1984 Mortuary Variability: An Archaeological Investigation. Orlando: Academic Press.

PARK, JIN-IL

2000 A Study of the culture of pottery with round clay stripes: Focused on Hoseo and Honam regions. Journal of the Honam Archaeological Society 12:125-161 (in Korean with English abstract).

PARK, SOON-BAL

1993a Bronze Age and Early Iron Age cultures in the Han River basin, in Cultural History of the Han River Basin: 127-168, ed. M.-L. Choi. Seoul: Mineumsa (in Korean).

1993b A thought on the spread of Early Iron Age culture. Journal of Archaeology and Art-History 3:2-23 (in Korean).

1998a A Study of State Formation of Paekje. Ph.D. diss. Seoul National University, Korea (in Korean with English abstract). 
1998 Synchronic and diachronic approaches to early Mahan society, in Studies on the History of Mahan: 7-50, ed. S.-B. Park. Daejeon: Chungnam National University Press (in Korean).

1999 Reconsideration of the formation of the Heunamni assemblage. Journal of the Hoseo Archaeological Society 1:35-57 (in Korean with English abstract).

2002 The formation and development of ancient villages, in Distinguished Lectures of Korean Ancient History, vol. 7:1-60. Seoul: Research Institute of Garakguk Heritage (in Korean).

Patterson, Thomas Carl

1991 The Inca Empire: The Formation and Disintegration of a Pre-Capitalist State. New York: Berg.

Peterson, Christian E., and Robert D. Drennan

2005 Communities, settlements, sites, and surveys: Regional-scale analysis of prehistoric human interaction. American Antiquity 70(1):5-30.

Pohl, Mary DeLand

1990 The Rio Hondo Project in Northern Belize, in Ancient Maya Wetland Agriculture: Excavations on Albion Island, Northern Belize: 1-19, ed. M. D. Pohl. Boulder: Westview Press.

Price, T. Douglas, and Gary M. Feinman

1995 Foundations of prehistoric social inequality, in Foundations of Social Inequality: 3-11, ed. T. D. Price and G. M. Feinman. New York: Plenum Press.

RenFrew, Colin

1974 Beyond a subsistence economy: The evolution of social organization in prehistoric Europe, in Reconstructing Complex Societies: An Archaeological Colloquium: 69-95, ed. C. B. Moore. Cambridge: American Schools of Oriental Research.

1976 Megaliths, territories and populations, in Acculturation and Continuity in Atlantic Europe, Mainly during the Neolithic Period and the Bronze Age: 198-220, ed. S. J. de Laet. Brugge: De Tempel.

ROH, HeE-SOOK

1998 A Study of the Bead in Korean Prehistory. M.A. thesis. Hanyang University, Ansan, Korea (in Korean with English abstract).

Roh, Hyuk-JiN

1997 Bronze Age society and economy, in Bronze and Iron Age Cultures: Korean History, vol. 3:267286. Gwacheon: National Institute of Korean History (in Korean).

2001 Reconsidering the grooved adzes. Komunhwa [Ancient Culture] 57:3-24 (in Korean with English abstract).

SCARborough, Vernon L.

1991 Water management adaptations in non-industrial complex societies: An archaeological perspective, in Archaeological Method and Theory, vol. 3:101-154, ed. M. B. Schiffer. Tucson: University of Arizona Press.

Schiffer, Michael Brian, and James M. Skibo

1997 The explanation of artifact variability. American Antiquity 62(1):27-50.

Service, Elman R.

1962 Primitive Social Organization: An Evolutionary Perspective. New York: Random House.

SHELACH, GIDEON

1999 Leadership Strategies, Economic Activity, and Interregional Interaction: Social Complexity in Northeast China. New York: Kluwer Academic/Plenum.

Shoda, SHINYA

2009 Production and Society in the Southern Korean Bronze Age. Seoul: Hakyeonmunhwasa.

Smith, Michael ERnest

1987 Household possessions and wealth in agrarian states: Implications for archaeology. Journal of Anthropological Archaeology 6(3): 297-335.

2012 The Comparative Archaeology of Complex Societies. New York: Cambridge University Press.

SON, JoON-Ho

2004 A study on the characteristics of Gwanchang-ri B Site based on the analysis of polished stone tools. Journal of the Korean Archaeological Society 51:5-31 (in Korean with English abstract).

2009 Burial systems in the Bronze Age of the Hoseo area. Prehistory and Ancient History 31:137-160 (in Korean with English abstract).

SONG, MAN-Young

1995 Chronology and Characteristics of Middle Mumun Period. M.A. thesis. Sungsil University, Seoul, Korea (in Korean with English abstract). 
2001 Changes in settlement structure under agricultural intensification in South Korea, in Various Issues in Agriculture: Proceedings of the 25th Annual Meeting of the Archaeological Society of Korea, 2-3 November, Busan, Korea: 75-108. Busan: Korean Archaeological Society (in Korean).

2004 Current and future issues in studying Honam Bronze Age, in Outcome and Current Issues of Honam Archaeology: Proceedings of 12th Annual Meeting of the Honam Archaeological Society, 7 May, Mokpo, Korea: 59-81. Mokpo: Honam Archaeological Society (in Korean).

2007 Changes in settlement structures and social complexity in the Bronze Age, South Korea, in The Emergence of Ranked Societies and Chiefs: 25-60. Seoul: Sahoipyoungron and Korean Archaeological Society (in Korean).

Spencer, Charles S., And Elsa M. Redmond

1992 Prehispanic chiefdoms of the western Venezuelan Llanos. World Archaeology 24(1):34-57.

Spencer, Charles S., Elsa M. Redmond, and Milagro Rinaldi

1994 Drained field at La Tigra, Venezuelan Llanos: A regional perspective. Latin American Antiquity 5(2) : 119-143.

Stanish, Charles

1994 The hydraulic hypothesis revisited: Lake Titicaca basin raised fields in theoretical perspective. Latin American Antiquity 5(4):312-332.

Stark, Barbara L., and Barbara Ann Hall

1993 Hierarchical social differentiation among Late to Terminal Classic residential in La Mixtequilla, Veracruz, Mexico, in Prehispanic Domestic Units in Western Mesoamerica: Studies of the Household, Compound, and Residence: 249-273, ed. R. S. Santley and K. G. Hirth. Boca Raton: CRC Press.

TAINTER, JOSEPH A.

1977 Modeling change in prehistoric social systems, in For Theory Building in Archaeology: Essays on Faunal Remains, Aquatic Resources, Spatial Analysis, and Systemic Modeling: 327-351, ed. L. R. Binford. New York: Academic Press.

Tilley, Christopher Y.

1994 A Phenomenology of Landscape: Places, Paths, and Monuments. Oxford: Berg.

TOURTELLOT, Gair

1988 Developmental cycles of households and houses at Seibal, in Household and Community in the Mesoamerican Past: 97-120, ed. R. R. Wilk and W. Ashmore. Albuquerque: University of New Mexico Press.

Trigger, Bruce G.

1990 Monumental architecture: A thermodynamic explanation of symbolic behaviour. World Archaeology 22(2) : 119-132.

Webster, Gary S.

1990 Labor control and emergent stratification in prehistoric Europe. Current Anthropology 31(4) :337-366.

Wilk, Richard R., And Robert McC. Netting

1984 Households: Changing forms and functions, in Households: Comparative and Historical Studies of the Domestic Group: 34-41, ed. R. M. Netting, R. R. Wilk, and E. J. Arnould. Berkeley: University of California Press.

Yi, GeON-Moo

1992a A preliminary classification of Songguk-ri type dwellings, in Papers in Honor of Retirement of Professor Heo Seon-Do: 913-933. Compiled by the Committee for Papers in Honor of Retirement of Professor Heo Seon-Do. Seoul: Ilchogak (in Korean).

$1992 b$ A study on the bronze ritual implement of prehistoric Korea. Journal of the Korean Archaeological Society 28:131-216 (in Korean).

1992c Bronze Age culture of Korea, in Bronze Age Culture of Korea: 125-142. Seoul: The National Museum of Korea (in Korean).

YI, KISUNG

2001 Changes in settlement patterns in the Plain Pottery Age of Chungnam, Korea. Journal of the Honam Archaeological Society 14:119-152 (in Korean with English abstract).

Yi, SEONBOK

1991 A critical reconsideration of the people-substitution model during the transition of Neolithic to Bronze Age, in Hanguk Godaesa Ronchong [Collection of Treatises from Ancient Korean History]: 1-21. Seoul: Research Institute for Korean Ancient Society (in Korean). 


\begin{abstract}
The transition from the Early to Middle Bronze Age in Korea witnessed emergent social complexity. Recently scholars have frequently referenced theoretical constructs developed in Western archaeology in attempts to understand the socioeconomic changes that occurred during this transition. Meanwhile, other researchers have realized that the Korean case can be seen as both compatible with and incompatible with aspects of these generalized socio-evolutionary models, and with specific cases of early complex society emergence elsewhere in the world. Synthesizing the current discussion of these issues, I argue that sociopolitical development in the central and southern parts of the Korean Peninsula during the EBA-MBA transition might have been closely related to economic intensification. This can be understood from a perspective that emphasizes elite control over basic economic resources as a significant factor in this development. However, it is not solely intended here to reveal compatibility or slight incompatibility between generalized theoretical discourse on complex society emergence in various regions of the world and the archaeological case of the Korean Bronze Age. Rather, the aim is to look for potential ways in which Korean Bronze Age archaeology can contribute to future discussion on this significant global topic of archaeological research, which has great promise in Korean Bronze Age studies but has not been very rigorously explored. While presenting an overview of recent research on socioeconomic patterns, the article offers a more extended discussion of a couple of crucial issues in these Korean Bronze Age societies: the varying elite strategies for agricultural intensification and the conflicting factors in deciding household size and composition as an adaptive strategy, particularly in cases of primary producers. KeYwords: Korea, Bronze Age, social organization, agricultural intensification, political economy, comparative studies.
\end{abstract}

